\title{
OPEN Breeding for higher yield, early maturity, wider adaptability and waterlogging tolerance in soybean (Glycine max L.): A case study
}

Shivakumar Maranna ${ }^{1,2 \varpi}$, Vennampally Nataraj ${ }^{1,2}$, Giriraj Kumawat ${ }^{1,2}$, Subhash Chandra ${ }^{1,2}$, Vangala Rajesh ${ }^{1}$, Rajkumar Ramteke ${ }^{1}$, Ram Manohar Patel ${ }^{1}$, Milind B. Ratnaparkhe ${ }^{1}$, S. M. Husain ${ }^{1}$, Sanjay Gupta ${ }^{1} \&$ Nita Khandekar ${ }^{1}$

Breeding for higher yield and wider adaptability are major objectives of soybean crop improvement. In the present study, 68 advanced breeding lines along with seven best checks were evaluated for yield and attributing traits by following group balanced block design. Three blocks were constituted based on the maturity duration of the breeding lines. High genetic variability for the twelve quantitative traits was found within and across the three blocks. Several genotypes were found to outperform check varieties for yield and attributing traits. During the same crop season, one of the promising entries, NRC 128, was evaluated across seven locations for its wider adaptability and it has shown stable performance in Northern plain Zone with $>20 \%$ higher yield superiority over best check PS 1347. However, it produced $9.8 \%$ yield superiority over best check in Eastern Zone. Screening for waterlogging tolerance under artificial conditions revealed that NRC 128 was on par with the tolerant variety JS 97-52. Based on the yield superiority, wider adaptability and waterlogging tolerance, NRC 128 was released and notified by Central Varietal Release Committee (CVRC) of India, for its cultivation across Eastern and Northern Plain Zones of India.

Soybean (Glycine max (L.) Merril) being the world's most important seed legume, has a prominent place among modern agricultural commodities. It contributes about $25 \%$ to the global edible oil production, about two thirds of the world's protein concentrate for livestock feeding and is a valuable ingredient in formulated feeds for poultry and fish. It is also an important raw material for food, pharma and other industries. As per AMIS, FAO estimates, among the major soybean growing countries, India ranks fourth in terms of area and fifth in terms of production. During 2020-21, soybean was grown in an area of 12.06 million hectare with a production of 13.58 million tons and productivity of $1126 \mathrm{~kg} / \mathrm{ha}$. Indian soybean productivity is stagnated around $1200 \mathrm{~kg} / \mathrm{ha}$ while world soybean productivity stands at $2900 \mathrm{~kg} / \mathrm{ha}$ and the USA and Brazil are the countries with highest productivity (>3000 kg /ha) (AMIS, FAO website). Lower soybean productivity in India is attributed to (1) rainfed nature and short duration (90-100 days) of the crop as compared to USA (160-170 days), (2) Emergence of biotic stresses particularly anthracnose, charcoal rot, and Rhizactonia aerial blight, and abiotic stresses like drought and waterlogging from past few years, and (3) narrow genetic base of the released cultivars and smaller $\mathrm{F}_{2}$ population size being used to identify the desirable segregants ${ }^{1}$. In any crop improvement program, breeders often keep in view a set of traits which, when brought together into a genotype would lead to high performance and such genotype is termed as ideotype ${ }^{2}$. The idea behind ideotype-design is to increase crop performance through the selection of genotypes based on multiple traits simultaneously ${ }^{3}$. Smith-Hazel (SH) index is a linear selection index that has been widely employed by breeders for multi-trait selection ${ }^{4,5}$. However, presence of multicollinearity and difficulty in assigning economic weightage to the traits under consideration in case of SH index can affect the genetic gain ${ }^{3}$. Therefore, to overcome these weaknesses, a multivariate selection index genotype-ideotype distance index (MGIDI) has been developed ${ }^{3}$ that accounts for the multicollinearity issue and selects all the traits under consideration favorably, thus resulting in significant genetic gain. 
While dealing with quantitative and complex traits such as grain yield, effects of $\mathrm{G} \times \mathrm{E}$ interactions needs to be considered for genotypic evaluation and varietal selection ${ }^{6,7}$. Various stability models have been developed to understand the $\mathrm{G} \times \mathrm{E}$ interaction patterns ${ }^{8,9}$. Interactions become complex as the number of environments and genotypes increase, and detail analysis and understanding cannot be possible without a graphic approach. GGE (Genotype main effect (G) plus genotype by environment interaction (GE)) is a multivariate, graphic based stability model that has been extensively employed in stability analysis and in understanding Genotype $\times$ Environment Interactions, more commonly for grain yield ${ }^{10}$.

Waterlogging is a major abiotic stress significantly affecting world soybean production, causing $16 \%$ yield loss globally ${ }^{11,12}$ and $18 \%$ yield loss in India ${ }^{13}$. Further, global climate change-based weather simulation models showed an expected increase in loss of crop production due to flooding in near future ${ }^{14}$. During last five cropping seasons, major soybean growing regions of central India received more than $70 \%$ rainfall during August-September months, when the crop is at late vegetative stage or early reproductive stage in farmer fields ${ }^{15}$, indicating the potential threat of waterlogging stress to the soybean production. Importance of breeding for waterlogging tolerance has been reported in India ${ }^{15}$. JS 20-38 an advanced breeding line has been identified as potential donor for the waterlogging tolerance ${ }^{16}$.Genome-wide association mapping of waterlogging tolerance has identified large number of favorable flood-tolerant alleles and new genetic sources for use in soybean breeding for waterlogging tolerance ${ }^{17}$.Till date only one waterlogging tolerant variety JS $97-52$ is notified for cultivation in central zone and north-eastern zone of India. Utilizing this variety in the breeding program, some varieties JS 20-29, JS 20-69 and JS 20-98 were developed with objective of yield traits which were released for cultivation in Central Zone of India. So, there is a need to develop the variety which is having wider adaptability with waterlogging tolerance for other zones. In India, soybean crop especially in Eastern Zone comprising of Bihar, Chhattisgarh, Ranchi states affected by waterlogging conditions due to prolonged monsoon rains. In our earlier studies conducted at ICAR-IISR, cultivar JS 97-52 has been reported as waterlogging tolerant genotype and it is being used as tolerant check in evaluation studies conducted in India ${ }^{18,19}$. A very few researchers evaluated Indian soybean genotypes for waterlogging tolerance either at vegetative or reproductive stage $\mathrm{e}^{20}$ but not at both stages. Keeping in view of soybean improvement under changing climate, the present study was undertaken to develop and evaluate several diverse breeding materials for identifying near-ideotype having higher yield potential, wider adaptability and waterlogging tolerance (Table 1).

\section{Results}

Genetic variability of quantitative traits. Significant genotypic difference $(p<0.05)$ was observed for traits under study within individual blocks viz., early, medium and late maturity blocks except for days to maturity in early block (Tables S1-S12). Pairwise comparison of the genotypes within the three groups was analyzed through LSD test $(P<0.05)$. In the early maturity (block 1$)$, with respect to grain yield/ plant, entry G21 (8-101-3), (93.9 g) was significantly superior to both the check varieties JS 20-34 and JS 95-60 whereas, G20 (6A-34-11) yielded (2470 g/plot) on par with check variety JS 20-34 (2344 g/plot). In block 2, G42 (6A-18-3-1) entry produced yield of $2230 \mathrm{~kg} /$ plot which is significantly higher than three checks JS 93-05, NRC 86 and JS 20-29. Similarly, in block 3, G54 (NRC 128) yielded $3833 \mathrm{~kg} /$ plot which is significantly higher than the rest of the tested entries across the block. However, as far as yield/plant is concerned it produced on par with two tested entries G 57 and G 62 (Table 2). As observed from violin plots (Fig. 1) and PCA (Fig. 2), overall, inflorescence length was highest in medium maturing group followed by early and late maturing groups. No of nodes per plant, No of branches per plant, No of pods per plant and biomass was recorded highest in late maturing group followed by medium and early maturing groups. Traits like 100 seed weight, harvest index, grain yield per plant and grain yield per plot were highest in case of early maturing group followed by late and medium maturing groups. Variability among the other traits across the blocks was shown in Table S2. Days to flowering was recorded in the range of 27-48 days. IC 15,089 an indigenous germplasm accessions flowered in only 27 days followed by entry (13-2) derived from NRC $86 \times$ MACS 330 (30 days). It matured earlier ( 89 days) when compared to the other entries, whereas JS $97-52$ took 48 and 100 days to flower and mature respectively. 100 seed weight was found highest (18.72 g) in G38 (6A-33-1-2) followed by G32 (8-94-3) and several entries exceeded the checks for trait 100 seed weight. The inflorescence length was found highest $(5.25 \mathrm{~cm})$ in G2 $(6 \mathrm{~A}-47-1)$ followed by G22 $(6 \mathrm{~A}-47-4)(4.76 \mathrm{~cm})$. Plant height was also showed wider range $(39.2-102.8 \mathrm{~cm})$ and highest plant height $(102.8 \mathrm{~cm})$ was recorded in the genotype G26 (13-100) followed by G14 $(100.8 \mathrm{~cm})(12-16)$ and JS 97-52 $(86.27 \mathrm{~cm})$.Biomass per plant $(\mathrm{g})$ was showed66.00-211.67 $\mathrm{g}$ range and highest was recorded in the line G54 (NRC 128). (Tables S13 and S14). Narrow differences between PCV and GCV indicated lesser influence of the environment for all the twelve traits. Number of branches per plant (44.98/32.16), yield/plant (43.05/33.72) and yield/plot (40.69/36.46) were recorded higher PCV and GCV than days to flower (14.00/13.62), days to maturity (6.19/5.65), 100 seed weight (13.83/10.02), plant height (21.41/17.92) and harvest index (25.95/11.93) whereas, higher heritability was found for days to flower (0.94), plot yield (0.80), inflorescence length $(0.74)$ and plant height (0.70) than the traits viz., harvest index (0.21), no. of branches (0.48) and 100 seed weight $(0.52)$. Similarly, highest genetic advancement was recorded for plot yield (1042.62) and lowest for the trait inflorescence length (1.65) (Table S13).

Correlation analysis. Correlation of yield with other traits in early maturing breeding lines revealed that grain yield per plant had significant positive correlation with 100 seed weight $\left(0.68^{\star * \star}\right)$, biomass $\left(0.90^{* *}\right)$, pods per plant $\left(0.65^{* * *}\right)$, branches per plant $\left(0.66^{* * *}\right)$ and days to flowering $\left(0.41^{\star}\right)$. In the medium maturing, yield per plant was significantly associated with harvest index $\left(0.72^{\star * \star}\right), 100$ seed weight $\left(0.74^{\star * \star}\right)$ and biomass $(0.83)$ but found non-significant negative association with days to flowering $(-0.22)$, plant height $(-0.21)$, days to maturity $(-0.18)$ and branches per plant $(-0.21)$. In case of late maturing breeding lines, yield per plant was significantly 


\begin{tabular}{|c|c|c|}
\hline Sl. no & Genotypes & Pedigree \\
\hline G1 & $3 \mathrm{~A}-44-1-3$ & Type $49 \times$ EC 538,828 \\
\hline G2 & $6 \mathrm{~A}-47-1$ & JS $335 \times$ EC 538,828 \\
\hline G3 & $3 \mathrm{~A}-60-6$ & Type $49 \times$ EC 538,828 \\
\hline G4 & $3 \mathrm{~A}-17-1-8$ & Type $49 \times$ EC 538,828 \\
\hline G5 & $3 \mathrm{~A}-60-2$ & Type $49 \times$ EC 538,828 \\
\hline G6 & $\mathrm{BC}_{3} \mathrm{~F}_{4}(\mathrm{JS} 95-60)-2$ & JS 95-60× G. soja \\
\hline G7 & $6 \mathrm{~A}-34-6$ & JS $335 \times$ EC 538,828 \\
\hline $\mathrm{C} 1$ & JS 20-34 (C) & JS 98-63×PK 768 \\
\hline $\mathrm{C} 2$ & JS 95-60 (C) & Selection from PS 73-22 \\
\hline G8 & $3 \mathrm{~A}-17-1-2$ & Type $49 \times$ EC 538,828 \\
\hline G9 & EC 572,109 & Germplasm collection \\
\hline G10 & $12-96$ & JS $20-38 \times$ JS 335 \\
\hline G11 & $12-22$ & JS $335 \times$ AGS 191 \\
\hline G12 & $3 A-93-1-2$ & Type $49 \times$ EC 538,828 \\
\hline G13 & 7A-68-1 & JS335 x EC 538,828 \\
\hline G14 & $12-16$ & JS $335 \times$ AGS 191 \\
\hline G15 & $8-24-2$ & JS $97-52 \times$ EC 538,828 \\
\hline G16 & $3 \mathrm{~A}-44-1-1$ & Type $49 \times$ EC 538,828 \\
\hline G17 & $13-2$ & NRC $86 \times$ MACS 330 \\
\hline G18 & IC 15,089 & Indigenous germplasm collection \\
\hline G19 & $8-98-1$ & JS 97-52×EC 538,828 \\
\hline G20 & 6A-34-11 (NRC 146) & JS $335 \times$ EC 538,828 \\
\hline G21 & $8-101-3$ & JS 97-52×EC 538,828 \\
\hline G22 & $6 \mathrm{~A}-47-4$ & JS $335 \times$ EC 538,828 \\
\hline G23 & $8-24-3$ & JS 97-52×EC 538,828 \\
\hline C3 & JS 93-05 & Secondary selectionfrom PS 73-22 \\
\hline G24 & $13-71$ & JS 97-52×JS 335 \\
\hline G25 & $14-52$ & Bragg x JS 335 \\
\hline $\mathrm{C} 4$ & JS 20-29 (C) & JS 97-52× JS 95-56 \\
\hline G26 & $13-100$ & JS 97-52×JS 335 \\
\hline G27 & $6 \mathrm{~A}-34-12$ & JS $335 \times$ EC 538,828 \\
\hline G28 & $15-64$ & Hardee x JS 335 \\
\hline G29 & $11-92$ & Doko x JS 335 \\
\hline G30 & $11-147$ & JS $335 \times$ AGS 191 \\
\hline G31 & $6 \mathrm{~A}-34-25$ & JS $335 \times$ EC 538,828 \\
\hline G32 & $8-94-3$ & JS $97-52 \times$ EC 538,828 \\
\hline G33 & $12-108$ & JS $20-38 \times$ JS 335 \\
\hline G34 & $15-77$ & G11 x JS 335 \\
\hline G35 & $15-72$ & Hardee x JS 335 \\
\hline G36 & $13-150$ & JS $335 \times$ JS 97-52 \\
\hline G37 & 6A-18-3-5 & JS $335 \times$ EC 538,828 \\
\hline G38 & $6 \mathrm{~A}-33-1-2$ & JS $335 \times$ EC 538,828 \\
\hline G39 & $232 \mathrm{D}$ & JS $335 \times$ G. soja \\
\hline G40 & $15-137$ & JS $335 \times$ AGS 191 \\
\hline G41 & $218 \mathrm{D}$ & JS $335 \times$ G. soja \\
\hline G42 & 6A-18-3-1 & JS $335 \times$ EC 538,828 \\
\hline G43 & $15-46$ & Kalitur x JS 335 \\
\hline G44 & $15-1$ & JS $335 \times$ MLT 1 \\
\hline G45 & $518 \mathrm{~L}$ & JS $335 \times$ G. soja \\
\hline C5 & NRC 86 (C) & RKS $15 \times$ EC 481,309 \\
\hline G46 & $8-66-2$ & JS 97-52×EC 538,828 \\
\hline C6 & JS 97-52 & PK $327 \times$ L129 \\
\hline G47 & 10-23-2-1 SP & Type $49 \times$ JS 335 \\
\hline G48 & $14-74$ & Bragg x JS 335 \\
\hline G49 & $14-77$ & Bragg x JS 335 \\
\hline G50 & NRC86 BC34 & NRC $86 \times$ G. soja \\
\hline
\end{tabular}




\begin{tabular}{|c|c|c|}
\hline Sl. no & Genotypes & Pedigree \\
\hline G51 & $14-143$ & Bragg x JS 335 \\
\hline G52 & $9-143$ & Multiparent cross \\
\hline G53 & $12-31$ & JS $20-38 \times$ JS 335 \\
\hline G54 & NRC 128 & JS $97-52 \times($ EC $389,148 \times$ PS 1042) \\
\hline G55 & $14-113$ & Bragg x JS 335 \\
\hline G56 & $12-63$ & JS $20-38 \times$ JS 335 \\
\hline G57 & $6 \mathrm{~A}-58-5$ & JS $335 \times$ EC 538,828 \\
\hline G58 & $2 \mathrm{~A}-24-1$ & Type $49 \times$ EC 538,828 \\
\hline G59 & $12-71$ & JS $20-38 \times$ JS 335 \\
\hline G60 & 7A-123-2-1 & JS $335 \times$ EC 538,828 \\
\hline G61 & $13-119$ & JS $97-52 \times$ JS 335 \\
\hline G62 & $6 \mathrm{~A}-58-2$ & JS $335 \times$ EC 538,828 \\
\hline G63 & $13-41$ & JS $335 \times$ Gaurav \\
\hline G64 & $13-35$ & JS $335 \times$ Gaurav \\
\hline G65 & NRC37 BC3F4 & NRC $37 \times$ G. soja \\
\hline G66 & $226 \mathrm{D}$ & JS $335 \times$ G. soja \\
\hline G67 & $162 \mathrm{D}$ & JS $335 \times$ G. soja \\
\hline G68 & $122 \mathrm{~L}$ & JS $335 \times$ G. soja \\
\hline C7 & JS 20-69 & JS 97-52 X SL 710 \\
\hline
\end{tabular}

Table 1. List of genotypes along with pedigree used in the evaluation for yield and attributing traits.

\begin{tabular}{|c|c|c|c|c|c|c|c|c|}
\hline \multirow[b]{2}{*}{ Genotype } & \multicolumn{2}{|c|}{ Block I (early maturity) } & \multirow[b]{2}{*}{ Genotype } & \multicolumn{2}{|c|}{ Block II (medium maturity) } & \multirow[b]{2}{*}{ Genotype } & \multicolumn{2}{|c|}{ Block III (late maturity)) } \\
\hline & Yield/plot (g) & $\begin{array}{l}\text { Yield/plant } \\
(\mathrm{g})\end{array}$ & & Yield/plot (g) & $\begin{array}{l}\text { Yield/ plant } \\
(\mathrm{g})\end{array}$ & & Yield/plot (g) & $\begin{array}{l}\text { Yield/ plant } \\
\text { (g) }\end{array}$ \\
\hline $\mathrm{C} 1$ & $2344.3^{\mathrm{ab}}$ & $31.2^{\mathrm{jk}}$ & $\mathrm{C} 3$ & $1087.6 f^{-i}$ & $40.4^{\mathrm{e}-\mathrm{i}}$ & C6 & $1555.3^{\mathrm{d}-\mathrm{g}}$ & $51.5^{\mathrm{c}-\mathrm{f}}$ \\
\hline $\mathrm{C} 2$ & $1381.6^{\mathrm{e}-\mathrm{i}}$ & $35.6^{\mathrm{g}-\mathrm{k}}$ & $\mathrm{C} 4$ & $870.6^{g-j}$ & $42.2^{e-i}$ & C7 & $1867.7^{\text {cde }}$ & $46.2^{\mathrm{c-g}}$ \\
\hline G1 & $2212.3^{\mathrm{a}-\mathrm{c}}$ & $38.2 \mathrm{f}^{-\mathrm{k}}$ & $\mathrm{C} 5$ & $1138.3^{\mathrm{e}-\mathrm{h}}$ & $40.6^{\mathrm{e}-\mathrm{i}}$ & G46 & $1780.7^{\text {cdef }}$ & $45.9^{\mathrm{c}-\mathrm{g}}$ \\
\hline G10 & $1284.3 \mathrm{f}^{-\mathrm{i}}$ & $43.5^{\mathrm{e}-\mathrm{k}}$ & G24 & $1647.0^{\mathrm{cd}}$ & $48.1^{\mathrm{d}-\mathrm{h}}$ & G47 & $2155.7^{\mathrm{bc}}$ & $52.0^{\mathrm{c}-\mathrm{e}}$ \\
\hline G11 & $1395.6^{\mathrm{e}-\mathrm{i}}$ & $48.7^{\mathrm{c}-\mathrm{j}}$ & G25 & $967.0 f^{-j}$ & $52.2^{\mathrm{c-g}}$ & G48 & $1005.7^{\mathrm{i}-1}$ & $42.2^{\mathrm{c}-\mathrm{h}}$ \\
\hline G12 & $2175.3^{\mathrm{a}-\mathrm{c}}$ & $58.2^{\mathrm{b}-\mathrm{f}}$ & G26 & 904.0f. ${ }^{-j}$ & $45.3^{\mathrm{d}-\mathrm{i}}$ & G49 & $1141.0^{\mathrm{h}-\mathrm{k}}$ & $45.23^{\mathrm{c}-\mathrm{g}}$ \\
\hline G13 & $868.6^{\mathrm{ij}}$ & $39.3 \mathrm{f}^{-\mathrm{k}}$ & G27 & $2194.0^{\mathrm{a}}$ & $67.9^{\mathrm{a}-\mathrm{d}}$ & G50 & $1476.6^{\mathrm{e}-\mathrm{h}}$ & $59.73^{\mathrm{bc}}$ \\
\hline G14 & $1224.6^{\mathrm{g}-\mathrm{i}}$ & $44.8^{\mathrm{d}-\mathrm{k}}$ & G28 & $1210.3^{\mathrm{e}-\mathrm{g}}$ & $41.7^{\mathrm{e}-\mathrm{i}}$ & G51 & $1906.0^{\mathrm{cd}}$ & $58.43^{\mathrm{b}-\mathrm{d}}$ \\
\hline G15 & $1300.3 \mathrm{f}^{-\mathrm{i}}$ & $54.4^{\mathrm{c}-\mathrm{h}}$ & G29 & $1111.3 \mathrm{f}^{-\mathrm{i}}$ & $46.6^{\mathrm{d}-\mathrm{i}}$ & G52 & $619.0^{1}$ & $37.57^{\text {d-h }}$ \\
\hline G16 & $2246.6^{a-c}$ & $49.3^{\mathrm{c}-\mathrm{j}}$ & G30 & $1230.0^{\mathrm{ef}}$ & 38.1f. ${ }^{-i}$ & G53 & $1295.0^{g-i}$ & $48.50^{\mathrm{c}-\mathrm{g}}$ \\
\hline G17 & $1443.6^{\mathrm{d}-\mathrm{i}}$ & $32.3^{i-k}$ & G31 & $2191.0^{\mathrm{a}}$ & $76.2^{a-c}$ & G54 & $3833.3^{\mathrm{a}}$ & $113.58^{\mathrm{a}}$ \\
\hline G18 & $607.6^{j}$ & $25.0^{\mathrm{k}}$ & G32 & $1779.3^{\mathrm{b}-\mathrm{d}}$ & $76.8^{\mathrm{ab}}$ & G55 & $1175.6^{\mathrm{g}-\mathrm{j}}$ & $45.30^{c-g}$ \\
\hline G19 & $1683.6^{\mathrm{c}-\mathrm{h}}$ & $65.0^{\mathrm{b}-\mathrm{e}}$ & G33 & $1915.0^{\mathrm{a}-\mathrm{c}}$ & $52.2^{\mathrm{c}-\mathrm{g}}$ & G56 & $974.0^{\mathrm{i}-1}$ & $45.50^{\mathrm{c}-\mathrm{g}}$ \\
\hline G2 & $2243.3^{\mathrm{a}-\mathrm{c}}$ & $67.8^{\mathrm{bc}}$ & G34 & $1477.3^{\mathrm{de}}$ & $38.03 \mathrm{f}^{-\mathrm{i}}$ & G57 & $2359.3^{\mathrm{b}}$ & $96.7^{\mathrm{a}}$ \\
\hline G20 & $2470.3^{\mathrm{a}}$ & $55.5^{\mathrm{b}-\mathrm{g}}$ & G35 & 1058.0f. ${ }^{-j}$ & $27.3^{\text {hi }}$ & G58 & $1424.6 f^{-h}$ & $36.1^{\mathrm{e}-\mathrm{h}}$ \\
\hline G21 & $2236.0^{\mathrm{a}-\mathrm{c}}$ & $93.93^{\mathrm{a}}$ & G36 & $939.3 f^{-j}$ & $32.6 \mathrm{~g}^{-\mathrm{i}}$ & G59 & $1562.3^{\mathrm{d}-\mathrm{g}}$ & $55.6^{\mathrm{b}-\mathrm{e}}$ \\
\hline G22 & $2054.3^{\mathrm{a}-\mathrm{c}}$ & $66.0^{\mathrm{b}-\mathrm{d}}$ & G37 & $2094.6^{\mathrm{ab}}$ & $52.0^{c-g}$ & G60 & $2165.6^{\mathrm{bc}}$ & $75.4^{\mathrm{b}}$ \\
\hline G23 & $1943.3^{\mathrm{a}-\mathrm{e}}$ & $45.8^{\mathrm{d}-\mathrm{k}}$ & G38 & $1942.3^{\mathrm{abc}}$ & $83.9^{\mathrm{a}}$ & G61 & $1713.3^{\mathrm{d}-\mathrm{f}}$ & $61.4^{\mathrm{bc}}$ \\
\hline G3 & $1826.3^{b-f}$ & $76.4^{\mathrm{ab}}$ & G39 & $706.0^{j}$ & $23.3^{\mathrm{i}}$ & G62 & $1882.0^{\mathrm{cd}}$ & $97.6^{a}$ \\
\hline G4 & $1721.3^{\mathrm{c}-\mathrm{g}}$ & $33.60^{\mathrm{h}-\mathrm{k}}$ & G40 & $1931.0^{\mathrm{abc}}$ & $31.0^{\mathrm{g}-\mathrm{i}}$ & G63 & $866.33^{j-1}$ & $44.1^{\mathrm{c-g}}$ \\
\hline G5 & $1924.0^{\mathrm{a}-\mathrm{e}}$ & $46.6^{\mathrm{c}-\mathrm{k}}$ & G41 & $759.00^{\mathrm{ij}}$ & $34.3 \mathrm{f}^{-\mathrm{i}}$ & G64 & $985.0^{\mathrm{i}-1}$ & $45.4^{\mathrm{c}-\mathrm{g}}$ \\
\hline G6 & $2007.6^{\mathrm{a}-\mathrm{d}}$ & $34.8^{\mathrm{g}-\mathrm{k}}$ & G42 & $2230.0^{\mathrm{a}}$ & $64.8^{\mathrm{a}-\mathrm{e}}$ & G65 & $970.0^{\mathrm{i}-1}$ & $30.6 f^{-h}$ \\
\hline G7 & $2416.6^{\mathrm{ab}}$ & $53.0^{\mathrm{c}-\mathrm{i}}$ & G43 & $1212.3^{\mathrm{efg}}$ & $44.4^{\mathrm{d}-\mathrm{i}}$ & G66 & $1210.0^{g-j}$ & $28.8^{\mathrm{gh}}$ \\
\hline G8 & $1101.0^{\mathrm{h}-\mathrm{j}}$ & $40.6 f^{-\mathrm{k}}$ & G44 & $1636.6^{\mathrm{cd}}$ & $57.5^{b-f}$ & G67 & $760.3^{\mathrm{kl}}$ & $22.0^{\mathrm{h}}$ \\
\hline G9 & $1653.6^{\mathrm{c}-\mathrm{h}}$ & $26.9^{\mathrm{k}}$ & G45 & $841.0^{\text {hij }}$ & $41.7^{\mathrm{e}-\mathrm{i}}$ & G68 & $637.3^{1}$ & $22.0^{\mathrm{h}}$ \\
\hline
\end{tabular}

Table 2. Pair wise comparison of the advanced breeding lines within early, medium and late maturity groups. Pairwise comparison using LSD $(p<0.05)$. 

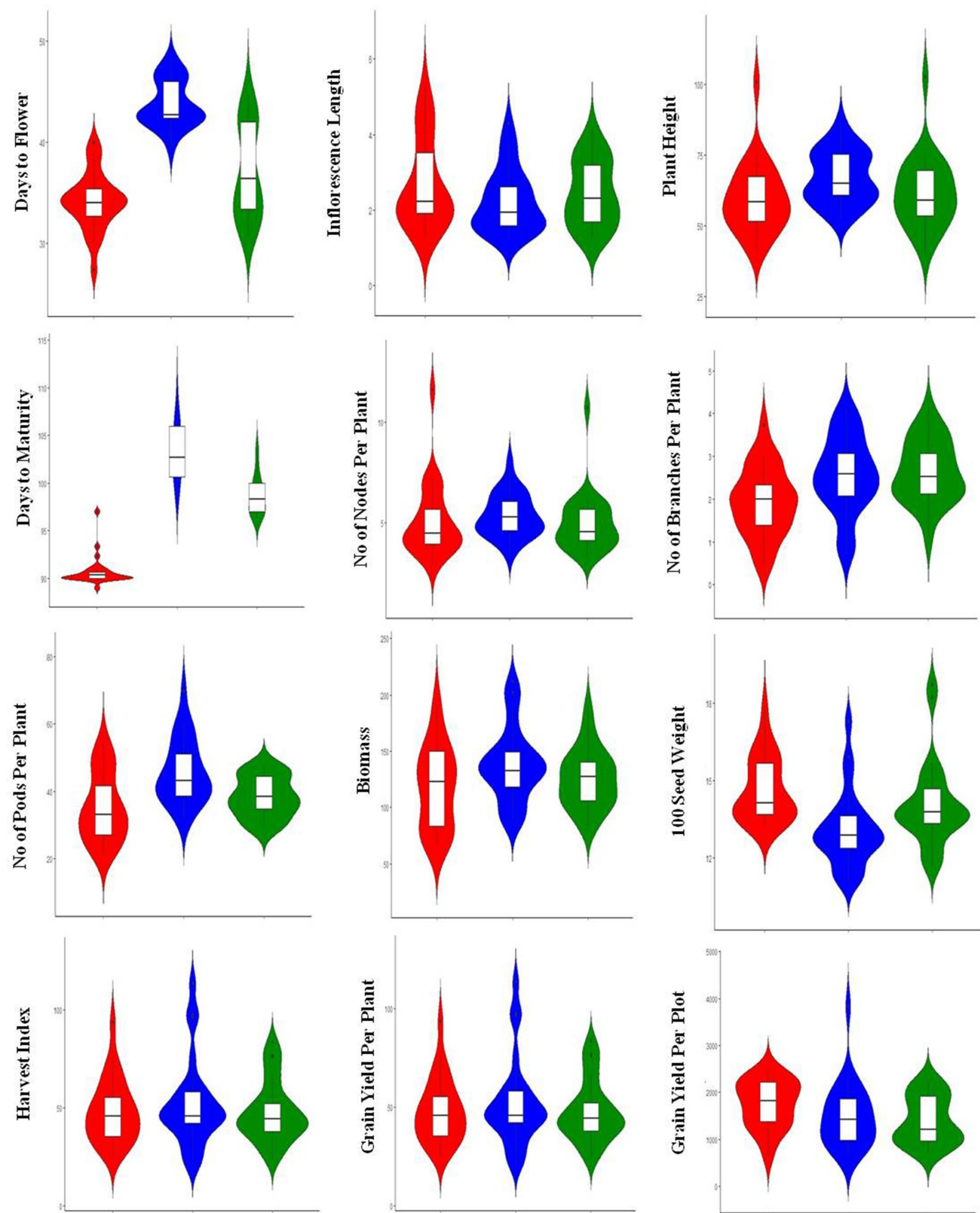

Early Maturing Late Maturing

Medium Maturing

Figure 1. Depiction of genetic variation through violin plots for different quantitative traits in early, medium and late maturing breeding lines. 


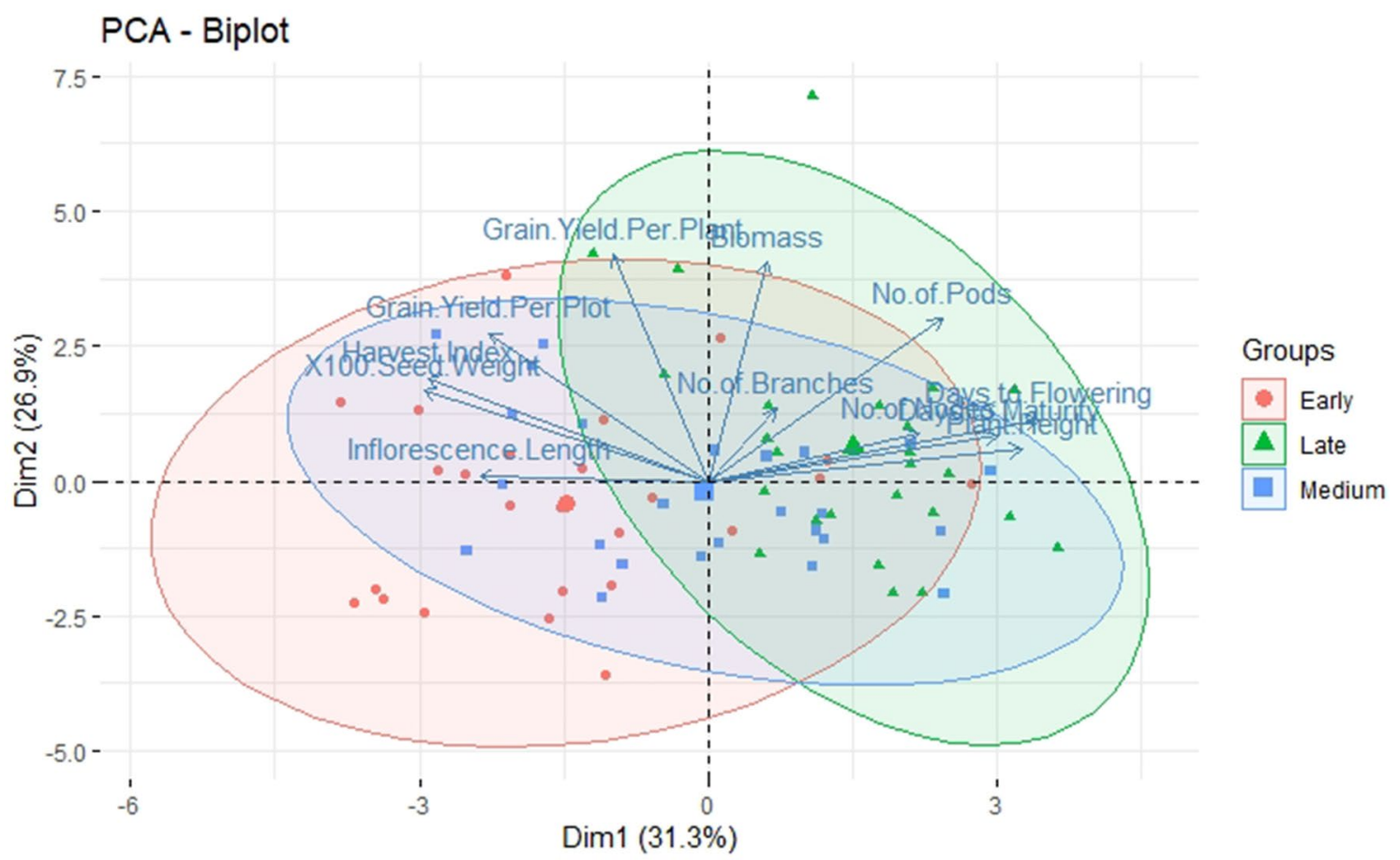

Figure 2. PCA for different quantitative traits in three different maturity groups (early, medium and late maturing genotypes).

associated with harvest index $\left(0.83^{\star * \star}\right)$, biomass per plant $\left(0.92^{\star * \star}\right)$, pods per plant $\left(0.56^{\star *}\right)$ and non-significant negative association was found with days to maturity $(-0.15)$. Inflorescence length was significantly positive association with grain yield per plot $\left(0.47^{\star}\right)$ (Fig. 3).

Cluster analysis. In the present study, days to flowering (52.25\%) exhibited greater variation and contribution to diversity among genotypes followed by days to maturity $(10.38 \%)$ and plot yield $(9.23 \%)$. Yield per plant $(1.15 \%)$, harvest index $(0.22 \%)$ and branches per plant $(1.73 \%)$ contributed comparatively less to the total diversity (Table 3). Seventy-five genotypes including seven checks grouped into five clusters based on $\mathrm{D}^{2}$ values using the Tocher's method. The distribution of genotypes into various clusters is depicted in Fig. S1 \& Table 4. Out of the five clusters, cluster I was the largest comprising of 57 genotypes followed by cluster II with 14 genotypes. Clusters III and V represented by one genotype each and two genotypes were presented in cluster IV. The average intra and inter cluster $\mathrm{D}^{2}$ values can be computed from the cluster diagram where the statistical distances among the 75 genotypes were exhibited (Table S15). Intra cluster D2 values ranged from zero to 6.79 with maximum distance in cluster 1 (8.04), followed by cluster IV (6.17). From the inter cluster $\mathrm{D}^{2}$ values of the five clusters, highest divergence was noticed between cluster II and V (19.76) while the lowest was noticed between cluster III and V (10.17). The cluster means for each of 12 characters (Table S16) indicated that the cluster mean for days to flowering was highest in cluster III (48.33) and the lowest in cluster II (31.67) and similar trend was noticed with days to maturity with respective clusters. 100-seed weight was highest in cluster II (14.70 g) and lowest in cluster III (12.37 g). Cluster V recorded the highest plot grain yield (3833.33 g) and the lowest was in cluster IV (1064.33). Cluster III was characterized by longest inflorescence $(4.29 \mathrm{~cm})$ while the shortest was recorded in cluster IV $(1.49 \mathrm{~cm})$. The number of pods per plant was highest in cluster V $(70.0)$ and the lowest number was noticed in cluster II (29.77). It was observed that cluster $\mathrm{V}$ had many of the desirable means for several characters and with respect to contribution to the genetic diversity.

Selection of genotypes based on MGIDI index and genetic gain. Based on multi-trait genotypeideotype distance index (MGIDI), eleven genotypes viz., G54 (NRC 128), G3 (3A-60-6), G57 (6A-38-5), G38 (6A-33-1-2), G21 (8-101-3), G32 (8-94-3), G31 (6A-34-25), G42 (6A-18-3-1), G57 (6A-38-5), G2 (6A47-1), G19 (8-98-1) and G16 (3A-44-1-1) were selected as superior to the others (Fig. 4). G61 (13-119) was very close to the cut point (blue line that indicates genotypes selected according to the selection pressure). The genetic gain results based on MGIDI revealed that MGIDI was the most efficient index to select genotypes with desired characteristics. The only trait with negative selection gain $(-1.91 \%)$ was observed with plant height. The highest genetic gain reported for plot yield (633) followed by biomass (33.8), yield per plant (24) and pods per plant (4.57) (Table 5).

Evaluation for waterlogging tolerance. Evaluation of three genotypes for waterlogging tolerance at vegetative stage revealed that NRC 128 performed on par with tolerant check JS 97-52 with respect to two important waterlogging tolerance traits viz., percentage reduction of chlorophyll content and seed yield. Per- 


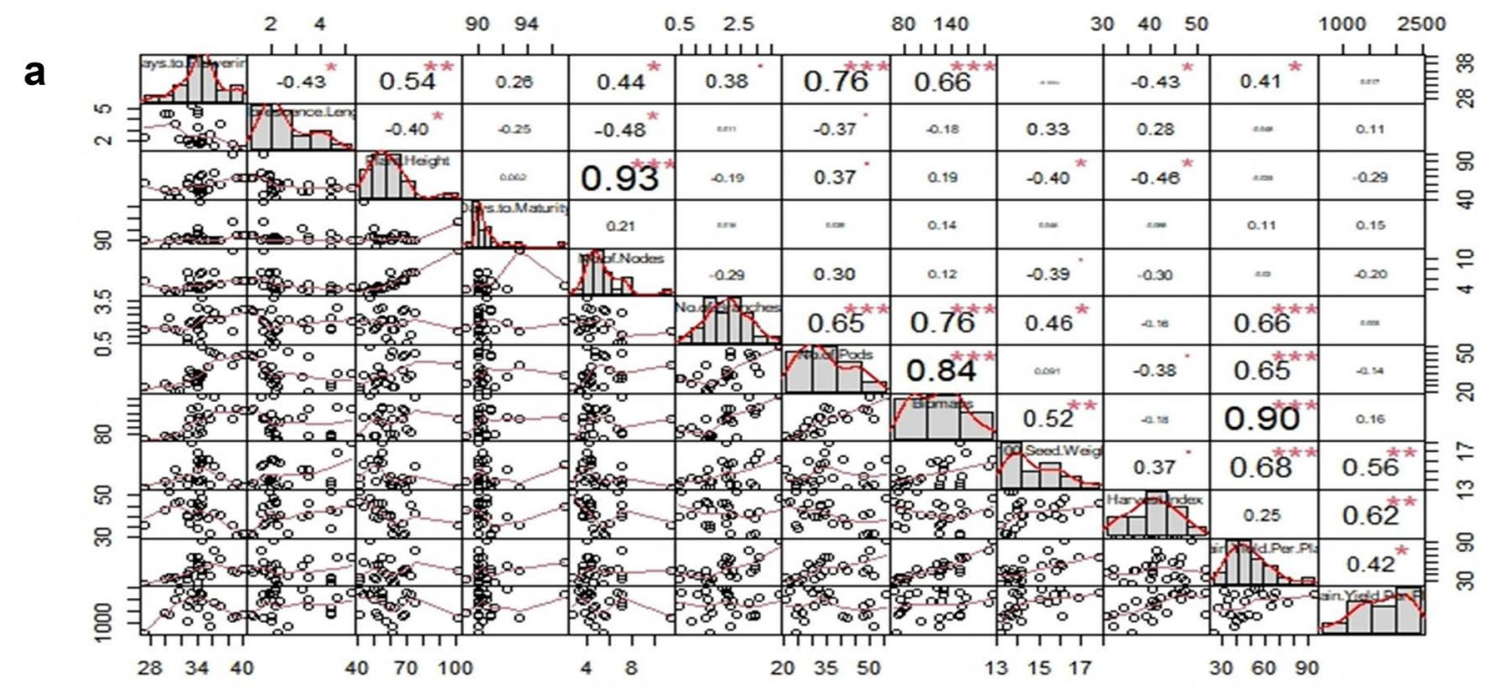

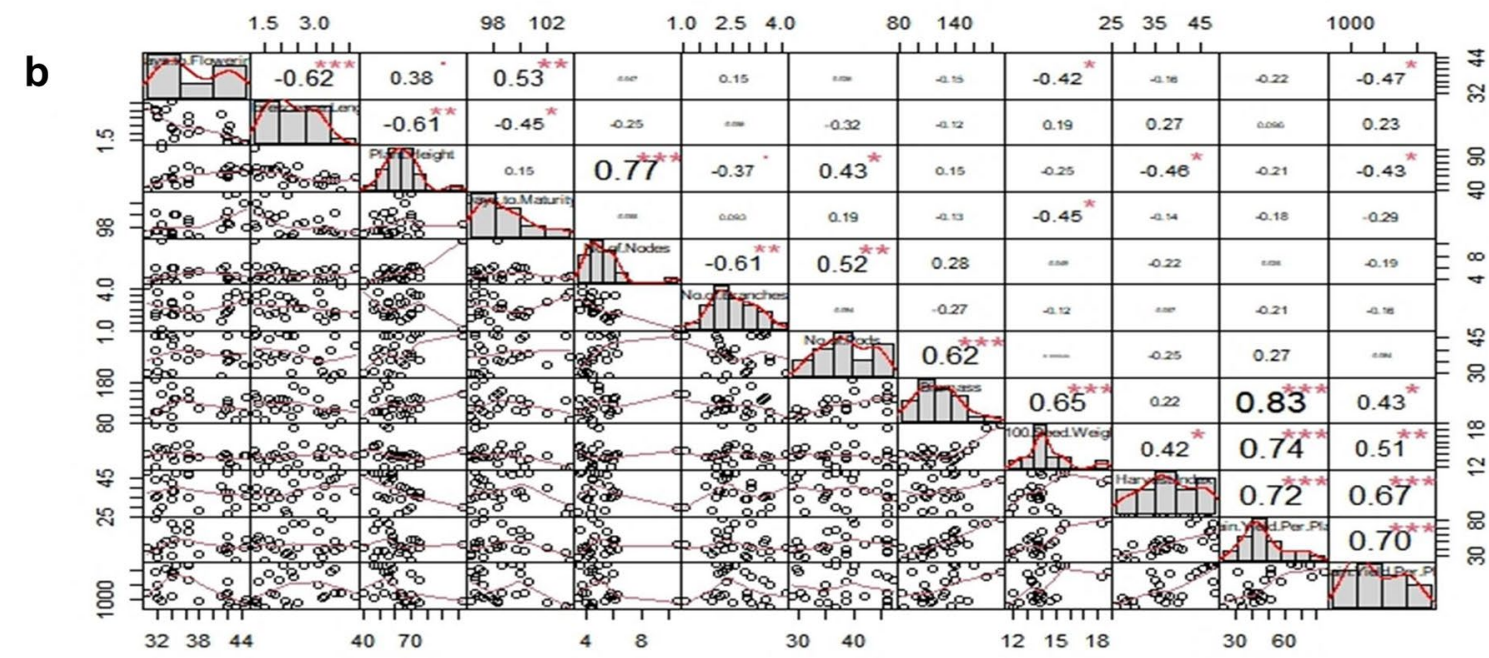

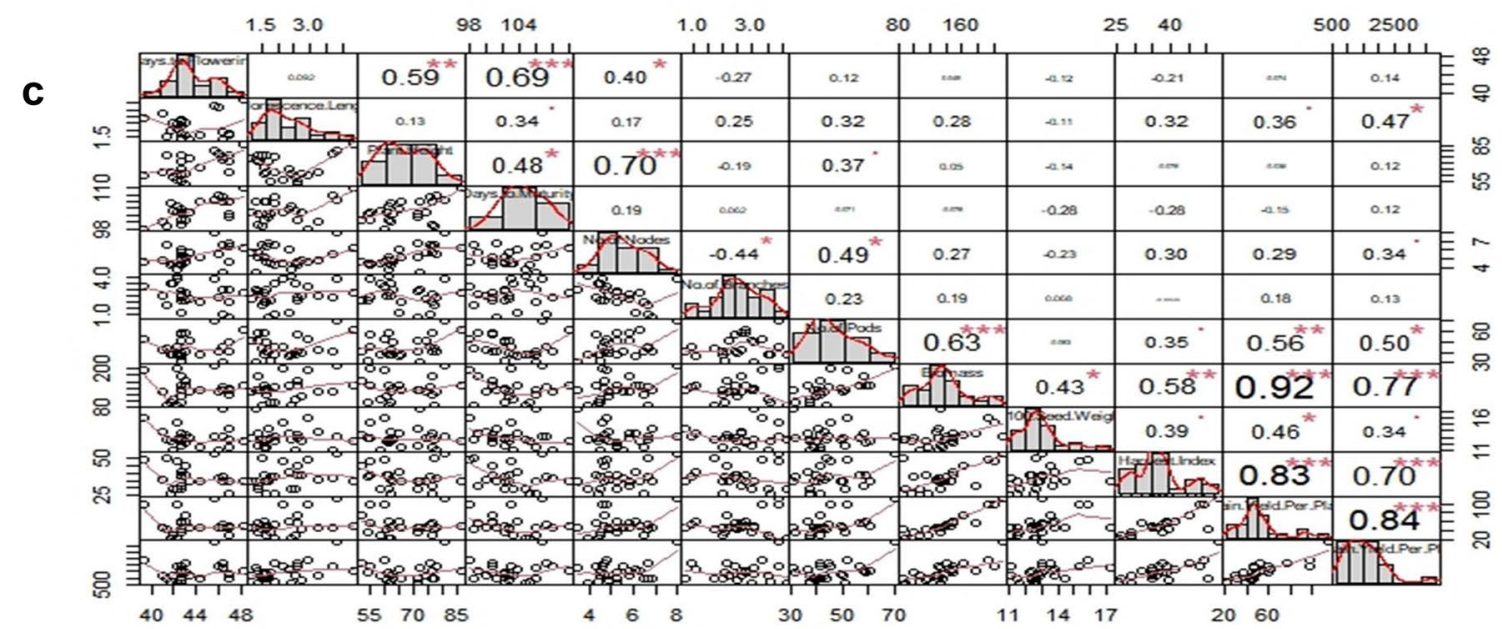

Figure 3. Correlation analysis in early (a), medium (b), late (c) maturing advanced breeding lines of soybean. (Generated using R package "PerformanceAnalytics version 2.0.4 URL https://github.com/braverock/Perfo rmanceAnalytics). 


\begin{tabular}{|l|l|l|}
\hline Source & Times ranked1st & Contribution (\%) \\
\hline 1 Days to flower & 1450 & 52.25 \\
\hline 2 Inflorescence length $(\mathrm{cm})$ & 225 & 8.11 \\
\hline 3 Plant height $(\mathrm{cm})$ & 116 & 4.18 \\
\hline 4 No. of nodes/Plant & 83 & 2.99 \\
\hline 5 No. of branches/Plant & 48 & 1.73 \\
\hline 6 No. of pods/Plant & 62 & 2.23 \\
\hline 7 biomass $(\mathrm{gm})$ & 167 & 6.02 \\
\hline 8 plot yield $(\mathrm{g})$ & 256 & 9.23 \\
\hline 9 yield/plant $(\mathrm{gm})$ & 32 & 1.15 \\
\hline 10 Days to maturity & 288 & 10.38 \\
\hline 11 100-Seed weight $(\mathrm{gm})$ & 42 & 1.51 \\
\hline 12 Harvest Index $(\%)$ & 6 & 0.22 \\
\hline
\end{tabular}

Table 3. Relative contribution of twelve different characters to total genetic diversity.

\begin{tabular}{|l|l|l|}
\hline Cluster & No. of lines & Genotype \\
\hline Cluster I & 57 & $\begin{array}{l}\text { G1, G3, G5, G7, G10, G11, G12, G13, G15, G16, G19, G21, G20, G23, C3, G24, G25, C4, G27, G29, G31, G32, } \\
\text { G33, G34, G36, G37, G39, G40, G41, G42, G43, G44, G45, C5, G46, G47, G48, G49, G50, G51, G52, G53, G55, } \\
\text { G56, G57, G58, G59, G60, G61, G62, G63, G64, G65, G66, G67, G68, C7 }\end{array}$ \\
\hline Cluster II & 14 & G2, G4, G6, C1, C2, G8, G9, G17, G18, G22, G28, G30, G35, G38 \\
\hline Cluster III & 01 & C6 \\
\hline Cluster IV & 02 & G14, G26 \\
\hline Cluster V & 01 & G54 \\
\hline
\end{tabular}

Table 4. Grouping of 75 advanced breeding lines into five different clusters based on twelve quantitatively contributing traits by $\mathrm{D} 2$ analysis.

centage reduction in root nodule dry weight, foliar damage score and plant survival rate were also relatively comparable with JS 97-52. Waterlogging tolerance coefficient was 77.65 for NRC 128 whereas it was 72.11 for JS 97-52, showing better performance of NRC 128 (Table 6). The susceptible check performed very poor when compared with JS 97-52 and NRC 128. Same genotypes were evaluated during reproductive stages, out of three, NRC 128 was found to perform on par (WLTI $=0.91)$ with JS 97-52 (WLTI $=0.90)$ in terms of reduction in seed yield per plant during waterlogging stress. In addition, it performed superior to best check in terms of 100 seed weight under stress conditions. Susceptible check, JS 90-41 found inferior in all the traits recorded when compared to tolerant check and NRC 128 (Table 7).

G $\times$ E analysis. For testing the superiority of promising genotype NRC 128 (L2),eleven other promising genotypes (RSC 11-07 (L1), AMS 2014-1 (L3), NRC 136 (L4), MACS 1493 (L5), RSC 11-03 (L6), NRCSL 1 (L7), NRC 132 (L8), NRC 137 (L9), JS 335 (L10), RKS 18 (L11) and JS 97-52 (L12)were evaluated at four locations Raipur, Dholi, Bhawanipatna and Ranchi (Eastern zone). Through mean vs stability analysis, RSC 11-07 was found to be high yielding $(1755.50 \mathrm{~kg} / \mathrm{ha})$ followed by NRC 128that produced $1720 \mathrm{~kg} / \mathrm{ha}$ of grain yield which was $9.76 \%$ higher yield than the best check JS 97-52(1552 kg/ha) (Fig. 5a). The 100 seed weight of the NRC 128 $(13.2 \mathrm{~g})$ was also higher than that of all the check entries (Table 8). On the other hand, RSC 11-07 was found to be near ideal genotype followed by NRC 136, AMS 2014-1 and NRC 128when mean performance and stability were considered simultaneously (Fig. 5b). Similarly, in Northern plain Zone, NRC 128 (L3) was evaluated along with five other promising entries viz., PS 1613 (L1), PS 1611 (L2), PS 1347 (L4), Pusa 97-12 (L5) and SL 958 (L6). It ranked first in terms of mean performance and stability by yielding $2242 \mathrm{~kg} /$ ha which was $20.6 \%$ higher than best check PS 1347 (1782 kg/ha) (Fig. 6a). Further, NRC 128 was ranked first with respect to ideal genotype (Fig. 6b). The mean multi-location data for grain yield (kg/ha) for NPZ and EZ has been presented in Tables S17 \& S18 respectively. Pooled ANOVA for genotypes evaluated across two agro-climatic Zones were presented in Table S19. Phenotype of NRC 128 has been depicted in the Fig. 7.

Offseason seed multiplication. For the seed requirement of the farmers, $477 \mathrm{~kg}$ (4.77 quintal) nucleus seed of NRC 128 was sown at Belagavi, Karnataka during February- May 2021. The variety was sown in area of 7.2 hectare and produced $7020 \mathrm{~kg}$ (70.20 quintal) seed with productivity of $975 \mathrm{~kg}$ per hectare.

\section{Discussion}

With the presence of narrow genetic base in soybean, use of diverse parents and development of large $\mathrm{F}_{2}$ population plays a vital role in development of high yielding varieties. Therefore, employing exotic germplasm accessions in hybridization program will helps in broadening the genetic base. Yield potential is built-up by progressive 


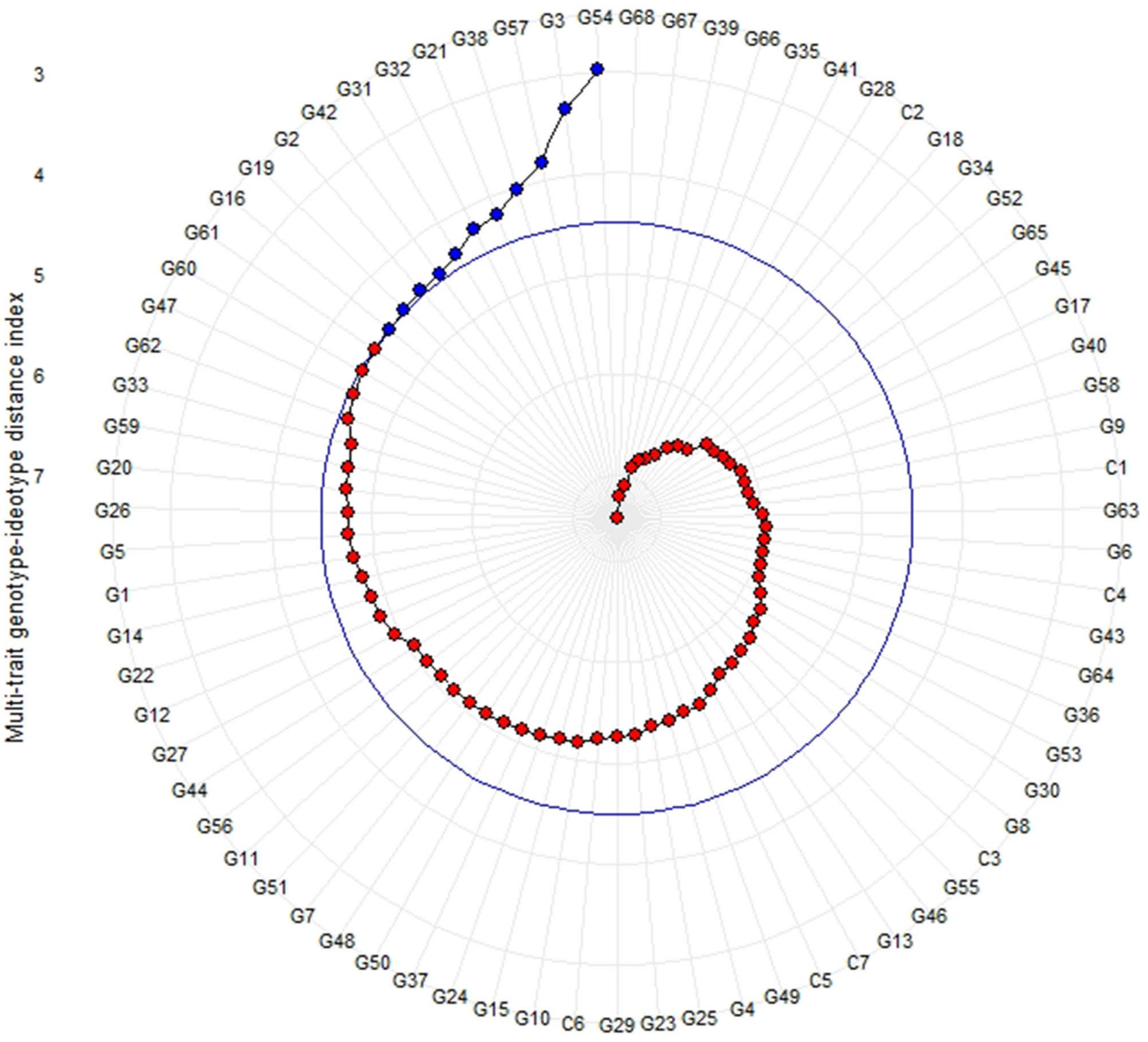

Nonselected Selected

Figure 4. MGIDI index and selection of superior genotypes (Generated using R Package 'metan' version 1.15.0 URL https://github.com/TiagoOlivoto/metan).

assembling of productivity genes as against quality, resistance to biotic and abiotic stresses ${ }^{21}$. In India, mega soybean varieties like Gaurav (JS 72-44), JS 335, JS 93-05 and JS 95-60 were bred through conventional breeding and aided in enhanced soybean production ${ }^{21}$. The annual genetic gain during 1969 to 1993 in seed yield of Indian soybean varieties has been about $22 \mathrm{~kg} / \mathrm{ha}^{22}$. Similar gain trend was also seen in other reports ${ }^{23}$.

For increasing the yield per se in soybean crop, conventional breeding must be reoriented with use of discreetly chosen parents and pre-bred diverse material in the crosses, sizeable $\mathrm{F}_{2}$ populations and three-way crosses, multiparent crosses and combination breeding ${ }^{21}$. An experiment was carried out in group balanced block design (GBBD) which is very efficient compared to regular RBD design. The GBBD design helps in reduction of experimental error by making blocks based on the maturity of the genotypes and treatments are compared with higher degree of the precision ${ }^{24}$. The presented study evaluated early, medium, and late maturing soybean advanced breeding lines for yield and attributing traits. The advanced breeding materials were derived from diverse crosses, including pre breeding material derived from wild type G. soja andmultiparent crosses. Two germplasm accessions EC 572,109 and IC 15,089 (triple mutant for e1, e3, e3) carrying early maturity alleles were also evaluated for yield and associated traits and both matured in $89-90$ days ${ }^{25}$. One of the advanced breeding line 13-2 derived 


\begin{tabular}{|l|l|l|l|}
\hline Factor & Traits & Objective & Genetic gain \\
\hline FA1 & Days to flowering & Decrease & -1.97 \\
\hline FA1 & No. of branches/ plant & Increase & 0.139 \\
\hline FA1 & No. of pods/plant & Increase & 4.57 \\
\hline FA1 & Days to maturity & Decrease & -2.20 \\
\hline FA2 & Biomass $(\mathrm{g})$ & Increase & 33.8 \\
\hline FA2 & Plot grain yield $(\mathrm{g})$ & Increase & 633 \\
\hline FA2 & Yield/plant $(\mathrm{g})$ & Increase & 24 \\
\hline FA2 & 100 seed weight $(\mathrm{g})$ & Increase & 1.38 \\
\hline FA2 & Harvest index $(\%)$ & Increase & 3.49 \\
\hline FA3 & Inflorescence length $(\mathrm{cm})$ & Increase & 0.471 \\
\hline FA3 & Plant height $(\mathrm{cm})$ & Increase & -1.91 \\
\hline FA3 & No. of nodes/plant & Increase & 0.227 \\
\hline
\end{tabular}

Table 5. Genetic gain for different traits based on MGIDI Index.

\begin{tabular}{|c|c|c|c|c|c|c|c|}
\hline Genotype & Foliar damage score & $\begin{array}{l}\text { Plant survival rate } \\
(\%)\end{array}$ & $\begin{array}{l}\text { Stem elongation } \\
\text { rate }(\%)\end{array}$ & $\begin{array}{l}\% \text { reduction in root } \\
\text { nodules dry weight } \\
\text { per plant }\end{array}$ & $\begin{array}{l}\% \text { reduction in } \\
\text { SCMR (SPAD } \\
\text { chlorophyll meter } \\
\text { readings) }\end{array}$ & $\begin{array}{l}\% \text { reduction in seed } \\
\text { yield per plant }\end{array}$ & $\begin{array}{l}\text { waterlogging } \\
\text { tolerance } \\
\text { coefficient }\end{array}$ \\
\hline NRC 128 & 2 & 95.59 & 103.57 & 6.45 & 14.92 & 18.77 & 77.65 \\
\hline $\begin{array}{l}\text { JS 97-52 (Tolerant } \\
\text { Check) }\end{array}$ & 1.67 & 97.37 & 118.81 & 5.92 & 15.39 & 25.96 & 72.11 \\
\hline $\begin{array}{l}\text { JS 90-41 (Suscepti- } \\
\text { ble Check) }\end{array}$ & 5.21 & 75.19 & 85.00 & 52.30 & 26.85 & 45.51 & 40.97 \\
\hline
\end{tabular}

Table 6. Evaluation of NRC 128 for waterlogging tolerance at vegetative stage $\left(V_{2}-V_{3}\right)$ under controlled conditions.

\begin{tabular}{|c|c|c|c|c|c|}
\hline Soybean genotypes & $\begin{array}{l}\text { \% reduction in total } \\
\text { chlorophyll content }\end{array}$ & $\begin{array}{l}\% \text { reduction in no. of pods } \\
\text { per plant }\end{array}$ & $\begin{array}{l}\% \text { reduction in } 100 \text { seed } \\
\text { weight }\end{array}$ & $\begin{array}{l}\% \text { reduction in seed yield } \\
\text { per plant }\end{array}$ & $\begin{array}{l}\text { waterlogging tolerance } \\
\text { index }\end{array}$ \\
\hline NRC 128 & 29.49 & 27.47 & 1.46 & 9.49 & 0.91 \\
\hline JS 97-52 (Tolerant Check) & 22.78 & 11.33 & 14.51 & 9.64 & 0.90 \\
\hline $\begin{array}{l}\text { JS 90-41 (Susceptible } \\
\text { Check) }\end{array}$ & 46.28 & 32.59 & 22.38 & 38.28 & 0.62 \\
\hline
\end{tabular}

Table 7. Evaluation of NRC 128 for waterlogging tolerance at reproductive (R1) stage under controlled conditions.

from MACS $330 \times$ NRC 86 where, MACS 330 (IC538550) is a source for photoperiod insensitivity and recessive alleles e2, e3-tr, and extra early maturity $(<85 \text { days })^{26}$. The early maturing breeding lines evaluated in block 1 , particularly those derived from crosses involving one of the parent as EC 538,828 was found to have higher 100 seed weight than other tested entries in block 2 and block 3. EC 533,828 is bold seeded genotype along with tolerance to drought and terminal heat stress ${ }^{27}$. Breeding for early maturity is much needed to fulfill the demand of the farmers in the Central India. In this region, early maturity soybean is primary requirement for soybeanpotato-wheat/soybean-wheat cropping system. In the present study, few early maturing breeding lines 6A-34-11 (NRC 146) (2470 kg/plot), 6A-34-6 (2416 kg/plot) and 3A-44-1-1 (2246 kg/plot) yielded on par with best early maturing check JS 20-34 (2344.33 kg/plot). The genotype NRC 146 was reported as heat tolerant ${ }^{28}$.

The response to selection in any crop improvement program depends on the degree of genetic variability and heritability ${ }^{29}$. High degree of genetic parameters such as heritability, variance, genetic advance, and genetic gain for the important traits like grain yield, biomass and others has been noticed in the current study. Correlation analysis in the present study revealed that improvement of higher yield is possible through selection of attributing traits such as biomass, harvest index, plant height, number of branches, number of pods, which was in accordance with previous reports $\mathrm{s}^{30,31}$. Soybean varieties with ideal inflorescence architecture could help in producing more yield potential. As an important and complex trait, inflorescence length (IL) of soybean significantly affected seed yields ${ }^{32,33}$. In the present study longest inflorescence was found in G2 (6A-47-1) genotype $(5.25 \mathrm{~cm})$ and it has also positive and significantly correlated with yield per plot $\left(0.47^{\star}\right)$. Cluster analysis helps in identification of distinct and diverse genotypes for the hybridization program to develop breeding material with broader genetic base. In the present study it grouped the accessions into five clusters with cluster I comprising of 57 accessions indicating close relatedness of the accessions and crossing among these accessions may yield less genetic gain. 

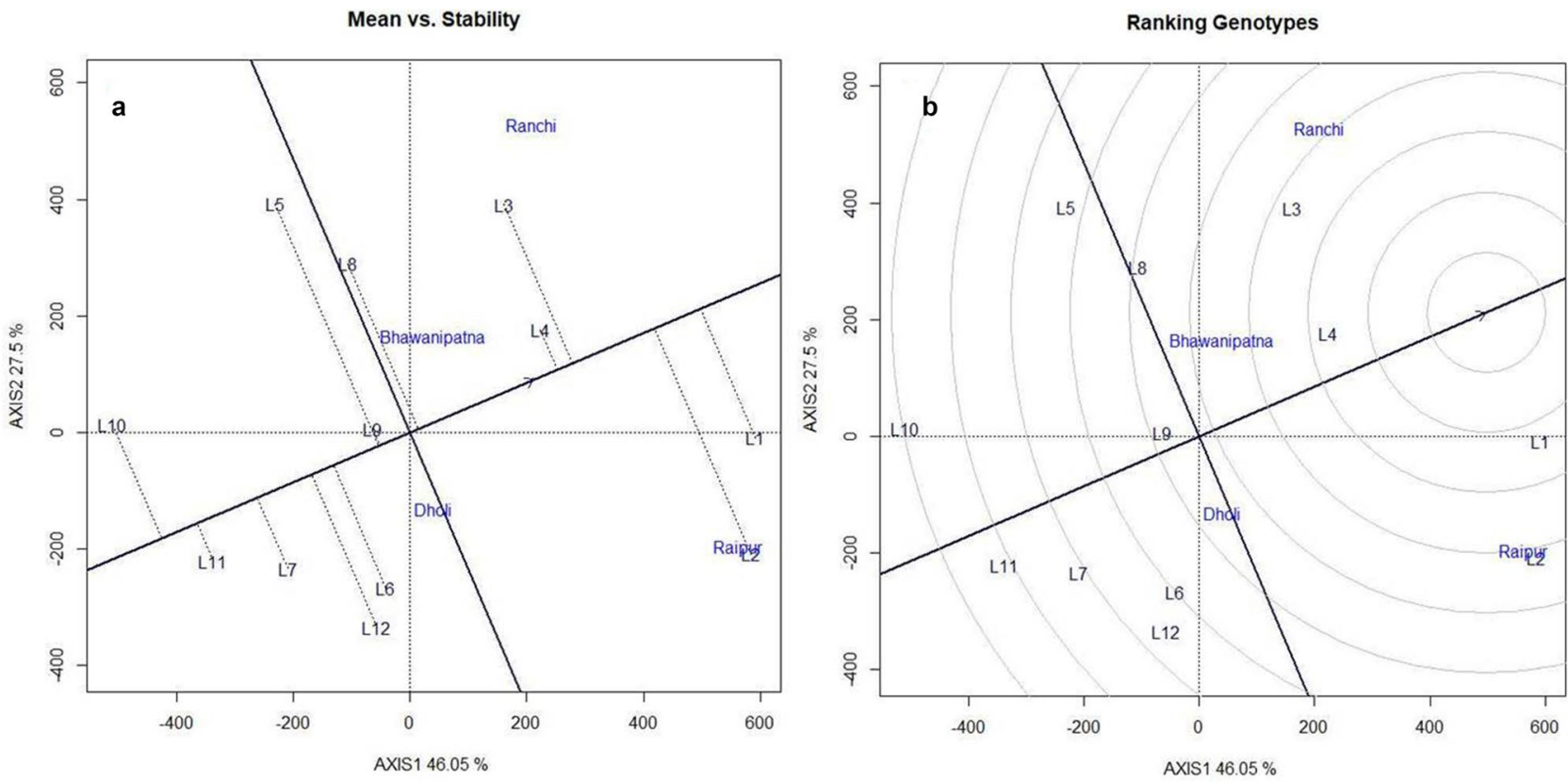

Figure 5. GGE Biplot analysis of genotypes evaluated in Eastern Zone: (a) Mean vs Stability analysis, (b)Ranking of genotypes based on ideal genotype: L1-RAC 11-07, L2-NRC 128, L3-AMS 2014-1, L4- NRC 136, L5- MACS 1493, L6- RSC 11-03, L7-NRCSL 1, L8-NRC 132, L9-NRC 137, L10-JS 335, L11-RKS 18 and L12- JS 97-52.

\begin{tabular}{|c|c|c|c|c|c|}
\hline Zone/Locations & Varieties & Mean yield (kg/ha) & Maturity (Days) & $100 \mathrm{SW}$ (gm) & $\begin{array}{l}\text { \% yield increase over } \\
\text { best check }\end{array}$ \\
\hline \multirow{4}{*}{$\begin{array}{l}\text { Eastern Zone (Bhawani- } \\
\text { patana, Dholi, Raipur, } \\
\text { Ranchi) }\end{array}$} & NRC 128 & 1720 & 106 & 13.2 & \multirow{4}{*}{9.76} \\
\hline & JS 335(Check) & 1394 & 105 & 10.46 & \\
\hline & RKS 18(Check) & 1444 & 107 & 11.47 & \\
\hline & JS 97-52(Check) & 1552 & 110 & 10.39 & \\
\hline \multirow{4}{*}{$\begin{array}{l}\text { Northern plain Zone } \\
\text { (Delhi, Ludhiana, Pant- } \\
\text { nagar) }\end{array}$} & NRC 128 & 2242 & 117 & 9.92 & \multirow{4}{*}{20.51} \\
\hline & Pusa 97-12(Check) & 983 & 121 & 8.01 & \\
\hline & PS 1347(Check) & 1782 & 123 & 8.94 & \\
\hline & SL 958(Check) & 1200 & 126 & 8.77 & \\
\hline
\end{tabular}

Table 8. Mean performance and superiority for agronomic traits of NRC 128 over best checks in Eastern Zone and Northern plain Zone.

Such reports on grouping of genotypes were done by other workers ${ }^{34,35}$. Clusters III and V had only one breeding line each indicating a high degree of heterogeneity, and these may be directly utilized as parents in hybridization programs to combine desirable characters. Similarly, hybridization between lines belonging to different clusters especially cluster II and V certainly is rewarding in generating diverse breeding material.

An efficient multivariate selection index, $\mathrm{MGIDI}^{2}$ was used to select genotypes nearer to ideotype. Based on this index, eleven genotypes were selected as superior to other tested entries and out of eleven, genotype G54 (NRC 128) is found to be ranked first in terms of ideotype. The genetic gain was positive for the traits under consideration except with plant height. Plant height had found negative gain may be due to its negative association with yield attributing traits viz., branches per plant, yield per plot, harvest index and 100 seed weight (Fig. S2). NRC 128 genotypes is derived from JS 97-52 x (EC 389,148 $\times$ PS 1042) and one of its parents, JS 97-52 is climate smart genotype having resistance for major disease of soybean such as charcoal rot and yellow mosaic disease, and tolerance to abiotic stresses like drought, heat, and waterlogging stresses ${ }^{36-40}$. JS 97-52 possesses 100 -seed weight of 8-9 gm, whereas in the NRC 128, 100 seed weight trait has been improved to $13.3 \mathrm{~g}$ and it was also least affected by waterlogging stress. The importance of GGE is demonstrated in number of other crops for yield and other agronomic traits ${ }^{41-46}$ to understand $\mathrm{G} x \mathrm{E}$ interaction pattern and to select stable and superior genotypes. Based on GGE biplots RSC 11-07 was found to be near-ideal genotype in Eastern Zone, while NRC 128 was found to be near-ideal genotype in Northern Plain Zone.

Substantial yield reductions in soybean have been observed when excessive soil water occurs during both vegetative and reproductive stages of the plant ${ }^{47-53}$. The most effective and economic approach to decrease yield loss is by developing waterlogging tolerant soybean cultivars ${ }^{17}$. Screening of genotypes at reproductive stages 

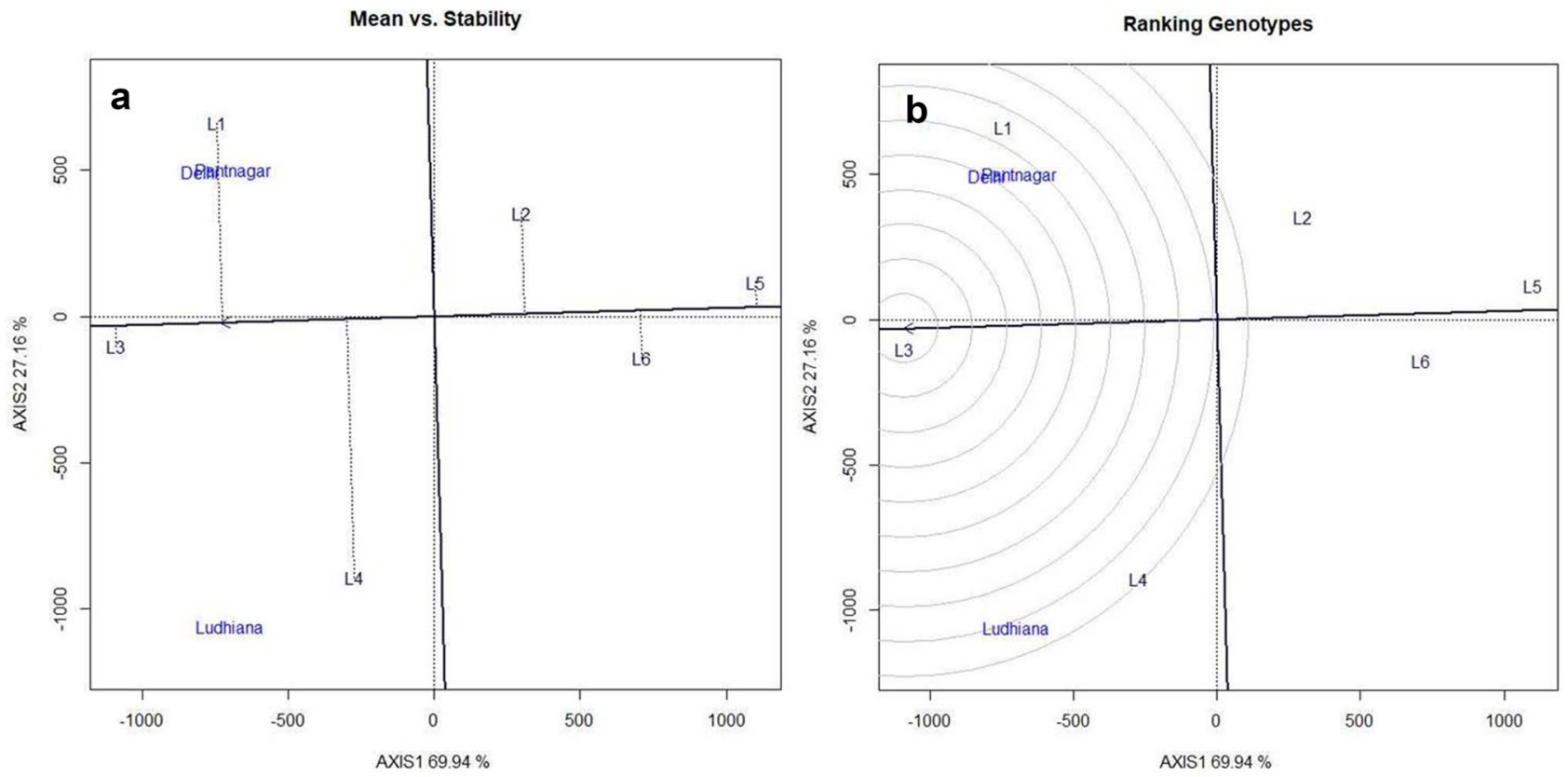

Figure 6. GGE Biplot analysis of genotypes evaluated in Northern Plain Zone: (a) Mean vs Stability analysis, (b) Ranking of genotypes based on ideal genotype: L1-PS 1613, L2-PS 1611, L3- NRC 128, L4- PS 1347, L5-Pusa 97-12 and L6-SL 958.

for identification of key genes and additional genetic resources for waterlogging tolerance was emphasized ${ }^{54}$. In the present study, NRC 128 exhibited waterlogging tolerant at both vegetative and reproductive stages. However, this genotype was found inferior for some traits i.e. stem elongation traits, pods per plant etc. under waterlogging stress, this type of observations were also reported by researchers in earlier study ${ }^{55}$. The present study observed that good grain filling during waterlogging stress at reproductive stage in NRC 128; therefore, it may be one of the candidate donor parents for development of varieties for the ecologies where more rainfall occurs near harvesting stage. Availability of quality seed is one of the primary requirements of the farmers to achieve more production. A total of 70.20 quintal of NRC 128 seed was produced for farmer's requirement. The variety as produced $975 \mathrm{~kg}$ per ha yield during off season which is considerably high.

\section{Conclusion}

Evaluation of large number of advanced breeding lines identified several promising lines for early maturity, bold seed, waterlogging tolerance and higher yield. The group balanced block design and MGIDI index used in the current study were found efficient and aided in identification of NRC 128, as high yielding and near-ideotype. Further, NRC 128 identified as first waterlogging tolerant variety for northern plain zone and especially for eastern zone of India where waterlogging situations occurs due to prolonged monsoon rains. Based on its superiority over yield and waterlogging tolerance, it has been released and notified (S.O. 500(E) 29.01.2021) by central varietal and release committee of Government of India for commercial cultivation in the states of Punjab, Uttar Pradesh (except Bundelkhand region of Uttar Pradesh), Delhi, West Bengal, Bihar, Jharkhand, Chhattisgarh, and Orissa.

\section{Material and methods}

Breeding trial. Sixty-eight advanced breeding lines derived from different crosses were evaluated for yield and attributing traits at ICAR-Indian Institute of Soybean Research, Indore, India. Group Balanced Block Design was followed for block-wise evaluation of early (up to 90 days), medium (up to 100 days) and late maturing (up to 110 days) genotypes. Genotypes were grouped into three blocks each with 25 genotypes including seven checks (early maturing checks -C1 (JS 20-34) and C2 (JS 95-60); medium maturing checks -C3 (JS 93-05), C4 (JS 20-29) and C5(NRC 86); late maturing checks -C6 (JS 20-69) and C7 (JS 97-52). The complete list of genotypes and their pedigree were presented in Table 1. Each genotype was evaluated in three replicates and each replication was sown in a plot of size $13.5 \mathrm{~m}^{2}$. Data on twelve quantitative traits viz., Days to flowering, Days to maturity, No. of branches, No. of nodes, Plant height $(\mathrm{cm})$, inflorescence length $(\mathrm{cm})$, No. of pods per plant, biomass per plant (g), 100 seed weight (g), harvest index (\%), grain yield per plot (g)and grain yield per plant (g) were recorded as per standard procedure (IBPGR 1984). Grain yield per plant was based on average yield (g) of five randomly selected plants. Recommended crop production package of practices has been followed throughout the experiment to reach maximum yield potential of the crop ${ }^{56}$. The methodology andprotocol used in the present study are in accordance with relevant institutional, national, and international guidelines and legislation. 

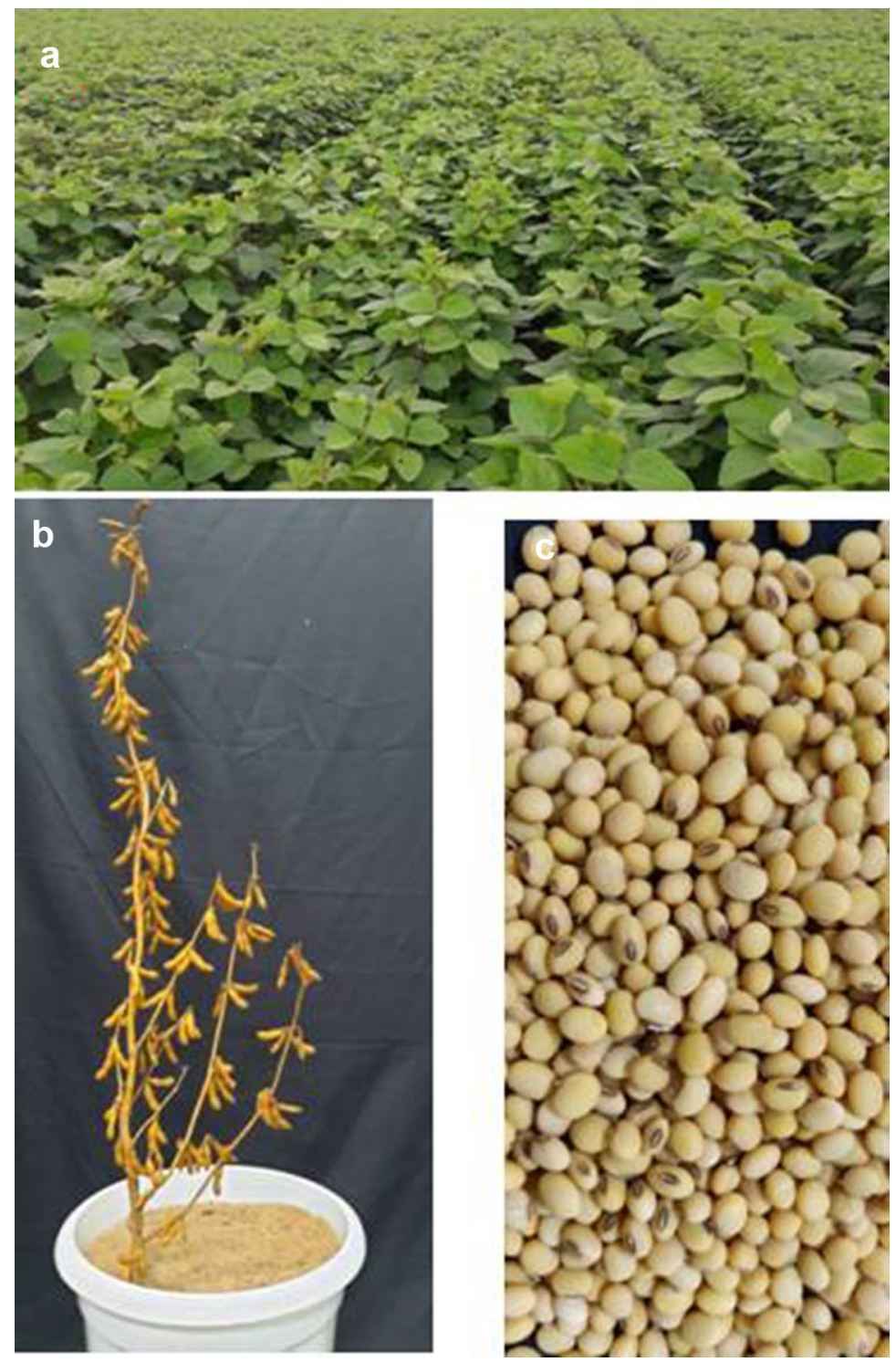

Figure 7. NRC 128 newly released waterlogging tolerant variety (a) Crop at vegetative sage (b) Single plant (c) Seed color and shape.

Evaluation for waterlogging tolerance. Three genotypes viz., NRC 128, JS 97-52, and JS 90-41 were evaluated for waterlogging tolerance at early vegetative and reproductive growth stages at ICAR-Indian institute of Soybean Research, Indore. As per our previous records NRC 128 was found promising and it has derived from the waterlogging tolerant variety JS 97-52; therefore, it was evaluated along with two check varieties for waterlogging tolerance under controlled conditions. All three genotypes were sown in three rows of one meter each and observations were recorded on every individual plant. For vegetative stages waterlogging tolerance, waterlogging stress was imposed during $\mathrm{V}_{2}-\mathrm{V}_{3}$ growth stages for 10 days by saturating the soil up to $10 \mathrm{~cm}$ above the soil surface in stress field plot while counter control field plot was maintained with normal irrigated condition using standard protocols ${ }^{57,58}$. Foliar damage score (FDS; 1-9 scale based on chlorosis, necrosis and plant mortality), plant survival rate (PSR $)^{59}$ and stem elongation rate (SER) in stressed plot were recorded. Plant survival rate was calculated as: $P S R=\{100-$ (number of plants before stress-number of plants after stress/ number of plants before stress) $\} \times 100$. Stem elongation rate (SER) was calculated as: $=($ height after stress- height before stress)/ height before stress $\times 100$. For determining the leaf chlorophyll content in both plots, five unrolled leaflets were randomly selected in each replicate using a chlorophyll meter (Konica Minolta, SPAD-502).Similarly, root nodule dry weight per plant in both plots (control and stress) was estimated as per methodology suggested ${ }^{60}$. After recording the yield traits and other related morpho-physiological traits in control and stress plots, percent reduction in grain yield per plant, root nodules' weight and SCMR (SPAD chlorophyll meter readings) under waterlogged conditions in comparison to normal field conditions was estimated. Waterlogging tolerance coefficient (WTC) was calculated with formula WTC=mean value (seed yield per plant) of treatment (genotype) in stressed plot $\times$ plant survival rate/mean value (seed yield per plant) of treatment (genotype) in control plot. 
Similarly, NRC 128 along with susceptible and tolerant check was evaluated for waterlogging tolerance at reproductive stage. Waterlogging stress was provided at $R_{1}$ stage (12-15 cm of water above the soil surface) for 15 days as per methodology with slight modifications ${ }^{61}$. These genotypes were evaluated for yield attributes ${ }^{62}$ and total chlorophyll content (through Acetone DSMO method) as per methodology from control and stress plot $^{63}$. Waterlogging tolerance was evaluated by dividing the seed yield of stressed plants by that of the control plants, to provide a waterlogging tolerance index (WTI $)^{64}$.

Multi-location evaluation. A total eleven genotypes along with NRC 128 was evaluated for yield in different locations of Eastern Zone (Dholi, Raipur, Ranchi, Bhavanipanta). Similarly, total of six genotypes including NRC 128 were evaluated at three locations viz., Delhi, Ludhiana and Pantnagar in North Plain Zone (of India. Multi-location trials were conducted in RBD fashion with four replicates each. Each replication is sown in a plot size of $21.6 \mathrm{~m}^{2}$ and the yield was converted into $\mathrm{kg} / \mathrm{ha}$. Recommended package of practiced were followed throughout the experiments ${ }^{56}$. Finally, nucleus seeds of NRC 128 genotype were multiplied in offseason at Belagavi, Karnataka (February-May 2021) for farmers requirement.

Statistical analysis. For the breeding trial, Analysis of Variance (ANOVA) was calculated as per Gomez and Gomez. Violin plots for different traits were generated using "ggplot2" R package ${ }^{65}$. Correlation analysis has been carried out using R package "PerformanceAnalytics" 66 . Principal Component Analysis was done using R packages "devtools" 67 and "factoextra" 68 . Cluster analysis was carried out using software "INDOSTAT". For multi-location trials, GGE Biplot analysis was done using R package "GGEBiplotGUI"69. MGIDI index was calculated using R package "Metan"

\section{Data availability}

The raw data supporting the conclusions of this manuscript will be made available by the authors to any qualified researcher. All datasets used for analysis in the study are included in the manuscript and as supplementary files.

Received: 21 August 2021; Accepted: 2 November 2021

Published online: 24 November 2021

\section{References}

1. Anonymous. Proceedings and Technical Programme, All India coordinated research Project on Soybean, Indian Institute of Soybean Research, Indore pp1-66. https://iisrindore.icar.gov.in/pdfdoc/TechnicalProgramme-2020-21.pdf_2020)

2. Donald, C. M. The breeding of crop ideotypes. Euphytica 17, 385-403 (1968).

3. Olivoto, T. \& Nardino, M. MGIDI: A novel multi-trait index for genotype selection in plant breeding. Bioinformatics https://doi. org/10.1101/2020.07.23.217778 (2020).

4. Hazel, L. N. The genetic basis for constructing selection indexes. Genetics 28, 476-490 (1943).

5. Smith, H. A. Discriminant function for plant selection. Ann. Eugenics 7, 240-250 (1936).

6. Kempton, R. A., \& Fox, P. N. Statistical Methods for Plant Variety Evaluation 1997 Chapman and Hall, London, p. 161 (1997)

7. Atlin, G. N., McRae, K. B. \& Lu, X. Genotype x region interaction for two-row barley yield in Canada. Crop Sci. 40, 1-6 (2000).

8. Finlay, K. W. \& Wilkinson, G. N. The analysis of adaptation in a plant-breeding program. Aust. J. Agric. Res. 14, 742-754 (1963).

9. Eberhart and Russell. Stability parameters for comparing varieties. Crop Sci. 6, 36-40 (1966).

10. Yan, W. \& Falk, D. E. Biplot analysis of host-by-pathogen data. Plant Dis. 86(12), 1396-1401 (2002).

11. Ahmed, F., Rafii, M.Y., Ismail, M.R., Juraimi, A.S., Rahim, H. A., Asfaliza, R., \&Latif, M. A.. Waterlogging tolerance of crops: breeding, mechanism of tolerance, molecular approaches, and future prospects. BioMed Research International: 1-10. (2013).

12. Boyer, J. S. Plant productivity and environment. Science 218, 443-448 (1982).

13. Soybean Processors Association of India, SOPA. https://www.thehindubusinessline.com/economy/agri-business/excess-rainstrim-soyabean-output-by-18-per-cent-to-899-lakh-tonnes-says-sopa/article29657049.ece. (2019).

14. Rosenzweig, C., Tubiello, F. N., Goldberg, R., Mills, E. \& Bloomfield, J. Increased crop damage in the US from excess precipitation under climate change. Glob. Environ. Chang. 12(3), 197-202 (2002).

15. Rajendran, A., \& Lal, S. K. Assessing the Need of Pre-germination Anaerobic Stress-Tolerant Varieties in Indian Soybean (Glycine $\max ($ L.) Merrill).National Academy Science Letter: 1-5. https://doi.org/10.1007/s40009-020-00937-9(2020).

16. Mamta A., Bhatia VS \& Ansari M.M. Screening Soybean (Glycine max) Genotypes for waterlogging Tolerance. National Symposium on Crop Improvement for Inclusive Sustainable Development at PAU, Ludhiana (7-9th November 2014).

17. Wu, C. et al. Genome-wide association mapping of flooding tolerance in soybean. Mol. Breed. https://doi.org/10.1007/s11032019-1086-0 (2020).

18. Anonymous.2015. Annual Report 2014-2015, Directorate of Soybean Research, Indore.

19. Anonymous.2016. Annual Report 2015-2016, ICAR-Indian Institute of Soybean Research, Indore.

20. Rajendran, A., Lal, S. K., Jain, S. K. \& Raju, D. Screening of soybean genotypes for pre-germination anaerobic stress tolerance to waterlogging. J. Pharmacognosy Phytochem. 2, 1-3 (2019).

21. Tiwari, S. P. Raising the yield ceilings in soybean: An Indian overview. Soybean Res. 12(2), 1-43 (2014).

22. Karmakar, P. G. \& Bhatnagar, P. S. Genetic improvement of soybean varieties released in India from 1969 to 1993. Euphytica 90 , 95-103 (1996).

23. Ramteke, R., Gupta, G. K., Muralidharan, P. \& Sharma, S. K. Genetic progress of soybean varieties released during 1969 to 2008 in India. Indian J. Genet. 71, 333-340 (2011).

24. Kwanchai, A.G., \& Arturo, A.G. Statistical procedure for Agriculture research. ISBN 978-81-265-2379-5. (2012).

25. Kumawat, G. et al. Genetic relationship, population structure analysis and identification of a triple recessive mutant of flowering and photoperiod sensitivity genes among Indian soybean Landraces. Physiol. Mol. Biol. Plants. https://doi.org/10.1007/s12298018-0615-3 (2019).

26. Bhatia, V. S. et al. MACS 330 (IC538550; INGR19016) a Soybean (Glycinemax germplasm with photoperiod insensitivity. Source recessive alleles e2, e3-tr, extra early maturity. Indian J. Plant Genet. Res. 33(2), 256-257 (2020).

27. Jumrani, K. \& Bhatia, V. S. Interactive effect of temperature and water stress on physiological and biochemical processes in soybean. Physiol. Mol. Biol. Plants 25(3), 667-681. https://doi.org/10.1007/s12298-019-00657-5 (2019).

28. Anonymous. Annual Report 2018-2019, ICAR-Indian Institute of Soybean Research, Indore. (2018)

29. Saroj, R. et al. Unravelling the relationship between seed yield and yield-related traits in a diversity panel of Brassica juncea using multi-traits mixed model. Front. Plant Sci. https://doi.org/10.3389/fpls.2021.651936 (2021). 
30. Nagarajan, D., Kalaimagal, T. \& Murugan, E. Evaluation of genetic parameters in M4 generation of soybean mutant lines. Int. J. Curr. Microbiol. App. Sci. 6(11), 2902-2906 (2017).

31. Li, M. et al. Identification of traits contributing to high and stable yields in different soybean varieties across three Chinese latitudes. Front. Plant Sci. 10, 1642. https://doi.org/10.3389/fpls.2019.01642 (2020).

32. Naoya, Y. et al. Mapping of quantitative trait loci associated with terminal raceme length in soybean. Crop. Sci. 54, 2461-2468 (2014).

33. Wang, J. et al. Genome-wide association study of inflorescence length of cultivated soybean based on the high-throughput singlenucleotide markers. Mol. Genet. Genom. https://doi.org/10.1007/s00438-019-01533-3 (2019).

34. Rana, C. et al. Characterisation of 4274 accessions of common bean (Phaseolus vulgaris L.) germplasm conserved in the Indian gene bank for phenological, morphological and agricultural traits. Euphytica 205, 441-457 (2015).

35. Shivakumar, M. et al. Yadav NAM population-A novel genetic resource for soybean improvement: Development and characterization for yield and attributing traits. Plant Genet. Resour. Characteriz. Utiliz. 17(6), 545-553. https://doi.org/10.1017/S147926211 9000352 (2019).

36. Bhatia, V. S. \& Kanchan, J. A maximin-minimax approach for classifying soybean genotypes for drought tolerance based on yield potential and loss. Plant Breed. https://doi.org/10.1111/pbr.12414 (2016).

37. Jumrani, K. \& Virender, S. B. Impact of combined stress of high temperature and water deficit on growth and seed yield of soybean. Physiol. Mol. Biol. Plants. 24(1), 37-50 (2018).

38. Jumrani, K. \& Virender, S. B. Combined effect of high temperature and water deficit stress imposed at vegetative and reproductive stages on seed quality in soybean. Ind. J. Plant Physiol. 23(2), 227-244 (2018).

39. Jumrani, K., Virender, S. B. \& Govind, P. P. Screening soybean genotypes for high temperature tolerance by in vitro pollen germination, pollen tube length, reproductive efficiency and seed yield. Ind. J. Plant Physiol. 23(1), 77-90 (2018)

40. Jumrani, K. \& Bhatia, V. S. Identification of drought tolerant genotypes using physiological traits in soybean. Physiol. Mol. Biol. Plants 25(3), 697-711 (2019).

41. Krishnamurthy, S. L. et al. Identification of megaenvironments and rice genotypes for general and specific adaptation to saline and alkaline stresses in India. Sci. Rep. https://doi.org/10.1038/s41598-017-08532 (2016).

42. Poli, Y. et al. Sarla Neelamraju Genotype $\times$ Environment interactions of Nagina22 rice mutants for yield traits under low phosphorus, water limited and normal irrigated conditions. Sci. Rep. 8, 15530. https://doi.org/10.1038/s41598-018-33812-1 (2018).

43. Djidonou, D. et al. Wallace4 \& Kevin C rosby Stability of yield and itscomponents in grafted tomato tested across multiple environments in Texas. Sci. Rep. 10, 13535. https://doi.org/10.1038/s41598-020-70548-3 (2020).

44. Balakrishna, D. et al. Detecting CSSLs and yield QTLs with additive, epistatic and QTLxenvironment interaction effects from Oryza sativa $\times$ O. nivara IRGC81832 cross. Sci. Rep. 10, 7766. https://doi.org/10.1038/s41598-020-64300-0 (2020).

45. Nataraj, V. et al. GGE biplot analysis of vegetable type soybean genotypes under multi-environmental conditions in India. J. Environ. Biol. https://doi.org/10.22438/jeb/42/2/MRN-1405 (2021).

46. Senguttuvel, P. et al. Evaluation of genotype by environment interaction and adaptability in lowland irrigated rice hybrids for grain yield under high temperature. Sci. Rep. 11, 15825. https://doi.org/10.1038/s41598-021-95264-4 (2021).

47. Scott, H. D., DeAngulo, J., Daniels, M. B. \& Wood, L. S. Flood duration effects on soybean growth and yield. Agron. J. 81, 631-636 (1989).

48. Scott, H. D., DeAngulo, J., Wood, L. S. \& Pitts, D. J. Influence of temporary flooding at three growth stages on soybean growth on a clayey soil. J. Plant Nutr. 13, 1045-1071 (1990).

49. Oosterhuis, D. M., Scott, H. D., Hampton, R. E. \& Wullschleger, S. D. Physiological response of two soybean [Glycine max (L.) Merr.] cultivars to short-term flooding. Environ. Exp. Bot. 30, 85-92 (1990).

50. Van Toai, T. T., Beuerlein, J. E., Schmitthenner, A. F. \& St Martin, S. K. Genetic variability for flooding tolerance in soybeans. Crop Sci. 34, 1112-1115 (1994).

51. Linkemer, G., Board, J. E. \& Musgrave, M. E. Waterlogging effect on growth and yield components of late-planted soybean. Crop Sci. 38, 1576-1584 (1998).

52. Reyna, N., Cornelious, B., Shannon, J. G. \& Sneller, C. H. Evaluation of a QTL for waterlogging tolerance in southern soybean germplasm. Crop Sci. 43, 2077-2082 (2003).

53. Alia, M. A., Guangnan, X., Jianbo, H., Tuanjie, Z. \& Tunyi, G. Detecting the QTL-allele system controlling seed-flooding tolerance in a nested association mapping population of soybean. Crop J. https://doi.org/10.1016/j.cj.2020.06.008 (2020).

54. Pan, J., Sharif, R., Xu, X. \& Chen, X. Mechanisms of waterlogging tolerance in plants: Research progress and prospects. Front. Plant Sci. 11, 627331. https://doi.org/10.3389/fpls.2020.627331 (2021).

55. Chandra S., Satpute G. K., Singh M., Nagar S., Kumawat G., Shivakumar M., Rajesh V., Arya M., Ratnaparkhe M.B., Nataraj V., Pandey S. and Gupta S. waterlogging tolerance in soybean at reproductive stage: traits and donors identified. Abstracts of International Web Conference on New Trends in Agriculture, Environment and Biological Sciences for inclusive Development during 21-22 June 2020. pp 188 (2020).

56. ICAR: Handbook of Agriculture. Indian Council of Agricultural Research, New Delhi, pp. 1143-1150 (2009).

57. Fehr, W. R., Caviness, C. E., Burmood, D. T. \& Pennington, J. S. Stage of development descriptions for soybeans, Glycine max (L.) Merr. Crop Sci. 11, 929-931 (1971).

58. Chandra S., Satpute G. K., Kumawat Giriraj, Singh Dipendra, Rajesh V., Ratnaparkhe M. B., Nataraj V., Singh M., Shivakumar M., Gupta S. \& Bhatia V.S. Standardization of screening technique for identifying waterlogging tolerant genotype at early vegetative stage in soybean. Abstracts of International Conference on Global Research Initiatives for Sustainable Agriculture \& Allied Sciences during 20-22 October 2019 at ICAR-National Acadamy of Agricultural Research Management, Hyderabad, Telangana (India) pp 16 (2019).

59. Wu, C. et al. An effective field screening method for flood tolerance in soybean. Plant Breed. 136(5), 710-719 (2017).

60. Lopez, S. M. et al. Nodulation and delayed nodule senescence: Strategies of two Bradyrhizobiumjaponicum isolates with high capacity to fix nitrogen. Curr. Microbiol. 75(8), 997-1005 (2018).

61. Wu, C. et al. Evaluation and development of flood-tolerant soybean cultivars. Plant Breed. https://doi.org/10.1111/pbr.12542 (2017).

62. International Board for Plant Genetic Resources (IBPGR), Descriptors of soybean. IBPGR Secretariat, Rome, IBPGR 1984/84/183.

63. Shinano, T., Lei, T. T., Kawamukai, T., Inoue, M. T. \& Koike, T. T. Dimethylsulfoxide method for the extraction of chlorophylls a and $b$ from the leaves of wheat, field bean, dwarf bamboo, and oak. Photosynthetica 32(3), 409-415 (1996).

64. Githiri, S. M., Watanabe, K. \& Harada, R. T. QTL analysis of flooding tolerance in soybean at an early vegetative growth stage. Plant Breed. 125(6), 613-618 (2006).

65. Wickham H. ggplot2. Elegant Graphics for Data Analysis. Springer-Verlag New York. ISBN 978-3-319-24277-4. https://ggplot2. tidyverse.org (2016).

66. Peterson, B.G., \& Carl, P. PerformanceAnalytics: Econometric Tools for Performance and Risk Analysis. R package version 1.5.2. https://CRAN.R-project.org/package=PerformanceAnalytics (2018).

67. Wickham, H., Jim, H., Winston, C. Devtools: Tools to make developing R packages easier. R package version 2.3.0. https://CRAN.Rproject.org/package $=$ devtools. $(2020)$.

68. Kassambara, A., Mundt, F. Factoextra: Extract and visualize the results of multivariate data analyses. R package version 1.0.7. https://CRAN.R-project.org/package=factoextra. (2020). 
69. Frutos, E., Galindo, M. P. \& Leiva, V. An interactive biplot implementation in R for modeling genotype-by-environment interaction. Stoch. Environ. Res. Risk Assess. 28, 1629-1641. https://doi.org/10.1007/s00477-013-0821-z (2014).

70. Olivoto, T. \& Lúcio, A. D. C. Metan: An R package for multienvironment trial analysis. Methods Ecol. Evol. 11, 783-789. https:// doi.org/10.1111/2041-210X.13384 (2020).

\section{Acknowledgements}

Authors gratefully acknowledge Director, Indian Institute of Soybean Research for supporting this investigation. The work is supported by in-house funding from the Institute Research Council approved project (Code NRCS1.1/87).

\section{Author contributions}

S.M., N.V., G.K. Conceived and designed the experiments: S.M., N.V., G.K., V.R., R.R. Performed the experiments: N.V., R.P. Analyzed the data: S.M., N.V. G.K., S.C., M.B.R.; Contributed to the writing of the manuscript, S.M., G.K., S.M.H. involved in development and selections of advanced breeding line: S.C. involved in Phenotyping for waterlogging tolerance; S.G. \& N.K. Multi-location evaluation and seed production activity; All the authors read and approved the manuscript.

\section{Competing interests}

The authors declare no competing interests.

\section{Additional information}

Supplementary Information The online version contains supplementary material available at https://doi.org/ 10.1038/s41598-021-02064-x.

Correspondence and requests for materials should be addressed to S.M.

Reprints and permissions information is available at www.nature.com/reprints.

Publisher's note Springer Nature remains neutral with regard to jurisdictional claims in published maps and institutional affiliations.

(c) (i) Open Access This article is licensed under a Creative Commons Attribution 4.0 International License, which permits use, sharing, adaptation, distribution and reproduction in any medium or format, as long as you give appropriate credit to the original author(s) and the source, provide a link to the Creative Commons licence, and indicate if changes were made. The images or other third party material in this article are included in the article's Creative Commons licence, unless indicated otherwise in a credit line to the material. If material is not included in the article's Creative Commons licence and your intended use is not permitted by statutory regulation or exceeds the permitted use, you will need to obtain permission directly from the copyright holder. To view a copy of this licence, visit http://creativecommons.org/licenses/by/4.0/.

(c) The Author(s) 2021 